Louisiana State University

LSU Digital Commons

June 2019

\title{
Evaluation of Post-Harvest Procedures for Quality Enhancement in the Louisiana Commercial Shrimp Industry
}

Nicholas Alan Haddad

Louisiana State University and Agricultural and Mechanical College

Follow this and additional works at: https://digitalcommons.Isu.edu/gradschool_theses

\section{Recommended Citation}

Haddad, Nicholas Alan, "Evaluation of Post-Harvest Procedures for Quality Enhancement in the Louisiana Commercial Shrimp Industry" (2019). LSU Master's Theses. 4956.

https://digitalcommons.Isu.edu/gradschool_theses/4956

This Thesis is brought to you for free and open access by the Graduate School at LSU Digital Commons. It has been accepted for inclusion in LSU Master's Theses by an authorized graduate school editor of LSU Digital Commons. For more information, please contact gradetd@lsu.edu. 


\title{
EVALUATION OF POST-HARVEST PROCEDURES FOR QUALITY ENHANCEMENT IN THE LOUISIANA COMMERCIAL SHRIMP INDUSTRY
}

\author{
A Thesis \\ Submitted to the Graduate Faculty of the \\ Louisiana State University and \\ Agricultural and Mechanical College \\ in partial fulfillment of the \\ requirements for the degree of \\ Master of Science
}

in

The School of Renewable Natural Resources

by

Nicholas Alan Haddad

B.S., University of Tampa, 2017

August 2019 


\section{ACKNOWLEDGEMENTS}

I would like to express how grateful I am for my thesis advisor Dr. Julie A. Lively of the School of Renewable Natural Resources at Louisiana State University. This research project would not be possible without her help, recommendations, and encouragement. She allowed me to independently work on projects, lab work, and writings while keeping her door open at all times to provide assistance when needed. Dr. Lively encouraged my interests and passions by continuously allowing me to partake in events outside of direct thesis research to build connections and enhance my knowledge and skillset in the fisheries science world. This work would not have been possible without the funding by NOAA Saltonstall-Kennedy Grant Award NA17NMF4270214.

I would like to thank my committee members Dr. Evelyn Watts of the Animal and Food Sciences Lab and Dr. Greg Lutz of the Aquaculture Research Station at Louisiana State University for their continued direction and guidance throughout the duration of this project. They kept me on track throughout the process and made sure I was taking suitable classes for my degree. I would also like to extend gratitude towards all my professors in the School of Renewable Natural Resources. In particular, Dr. William Kelso for his interesting lectures, duties as the graduate school coordinator, and of course, his biannual barbecues.

I would also like to thank everyone at Louisiana Sea Grant, specifically Thomas Hymel, Anne Dugas, and Julie Falgout, for their invaluable help in completing this research. This project would have been truly impossible without their assistance and the successful relationships they have built with fishermen over their careers. I would like to 
acknowledge our collaborating fishermen for allowing me the opportunity to join them on shrimp fishing trips and collect data whenever necessary.

I would like to give a special thanks and appreciation for my co-workers and friends from the Lively lab: Damen Pheiffer, Lauren Bonatakis and Lauren Carter for their help in all aspects of this project. My colleagues at the graduate school, especially my roommate Jacob Fetterman, made my time at Louisiana State University enjoyable and a tremendous experience. Finally, I would like to mention how thankful I am for my family and their continued support through my last six years of education. 


\section{TABLE OF CONTENTS}

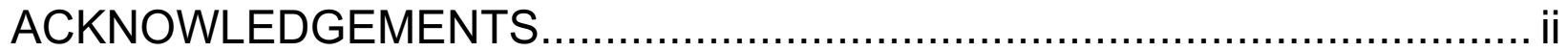

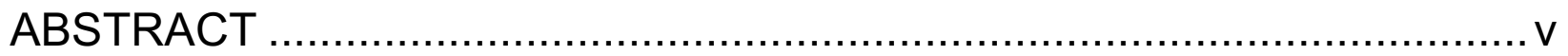

CHAPTER 1. REVIEW OF LITERATURE ..........................................

1.1. Economic Importance of the Louisiana Shrimp Fishery ...............................

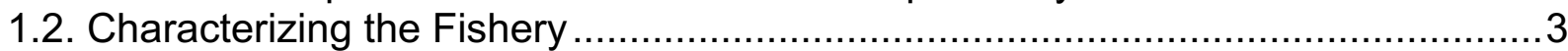

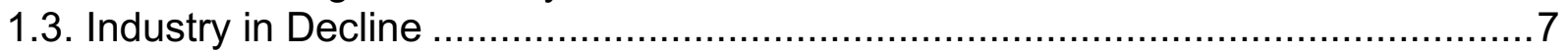

1.4. Consumer Quality and Awareness ........................................................ 12

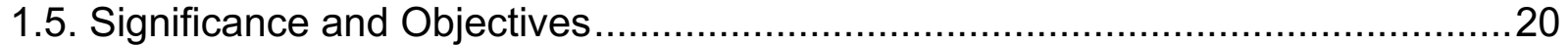

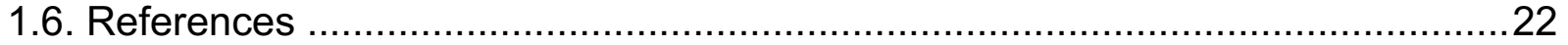

CHAPTER 2. LOUISIANA LIMITED WILD PLATE FROZEN SHRIMP ......27

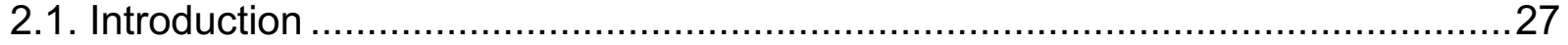

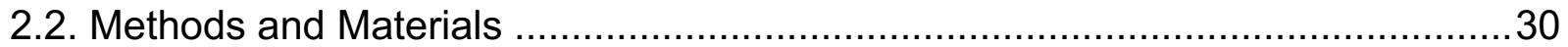

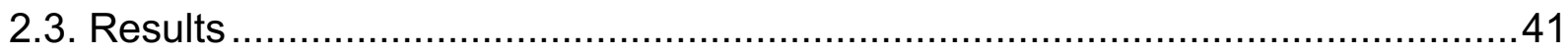

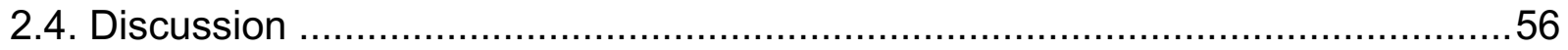

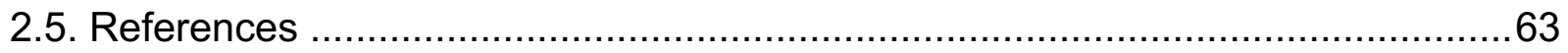

CHAPTER 3. THE EFFECT OF SALTBOXES ON SHRIMP AND BYCATCH IN THE LOUISIANA SHRIMP FISHERY ...........................67

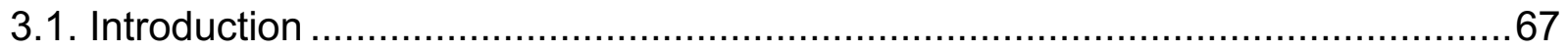

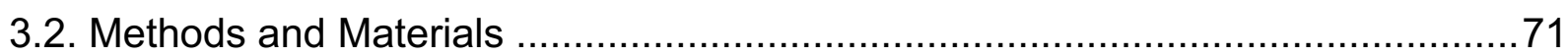

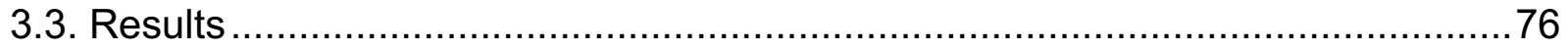

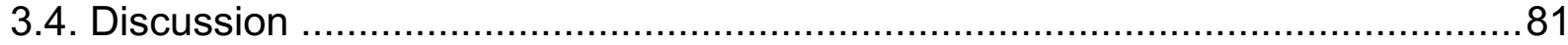

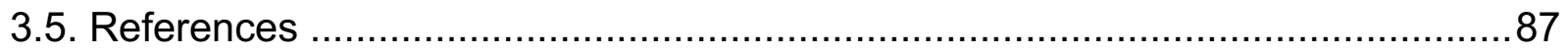

APPENDIX A. SURVEY IRB EXEMPTION ......................................90

APPENDIX B. PLATE FROZEN SHRIMP SURVEY .............................91

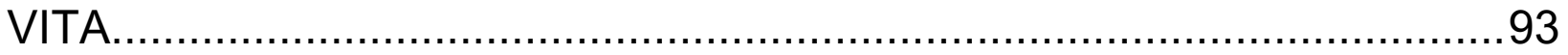




\begin{abstract}
The Louisiana commercial shrimp fishery has faced numerous challenges and is declining at an alarming rate. The opportunity may exist to add value to the industry by creating a superior product through optimal operating procedures. Post-harvest processes of plate freezing were analyzed to develop a high-quality shrimp product capable of fostering economic growth for fishermen. Quantifiable data was collected via overnight trips onboard plate freezing boats and at plate freezing docks. Sulfite-free melanosis prevention testing occurred by exploring the use of 4-hexylresorcinol treatments, in combination with vacuum packaging and modified atmosphere packaging, to delay the onset of black spot. Physical and chemical properties of plate frozen shrimp were analyzed from collaborating fishermen. Saltbox concentrations were examined for efficiency, potential mortality on blue crabs, and effect on residual salt content in shrimp tissue. Results found 4-hexylresorcinol products successfully inhibited black spot development for up to 10 days. Vacuum-packaging and modified atmosphere packaging did not have significant effects on melanosis inhibition. Juvenile and immature blue crabs were not significantly harmed by hypersaline conditions or the use of sulfites in saltboxes. The culling procedure can be significantly shortened through proper salinity use in a saltbox. The use of plate freezers both onboard and at docks has the potential to improve shrimp quality, as well as advance the economic stability of the industry.
\end{abstract}




\section{CHAPTER 1. REVIEW OF LITERATURE}

\subsection{Economic Importance of the Louisiana Shrimp Fishery}

\subsubsection{International Importance}

The commercial shrimp industry has been a vital component of the world's seafood market for more than a century. With the development of new gear types from otter trawls to butterfly nets to skimmers, the capture of wild caught shrimp increased tremendously during the $20^{\text {th }}$ century. At $17 \%$ of global seafood trade by value in 2006 , shrimp, both wild caught and farmed, were considered the most valuable seafood products in the world (FAO 2009, Asche et al. 2012). However, shrimp were surpassed in 2013 by trout and salmon and currently rank second in trade value (FAO 2016). Global trade of shrimp fell to around $15.3 \%$ in 2013 , however production has since increased (FAO 2016). As demand grew, countries took advantage of the opportunity to farm shrimp, and the aquaculture industry grew significantly in the early 1980's (Arquitt et al. 2005). Shrimp farming, especially in Asian countries, boomed in the early 2000's. From $2000-2007$, the shrimp capture rate rose steadily by around $13 \%$ while aquaculture production increased by $190 \%$ (Mine et al. 2016, FAO 2016). Today, more than half of the world's shrimp supply is farmed. Despite a slight setback and decline of world aquaculture production due to Early Mortality Syndrome (EMS) in farmed shrimp in the early 2010 's, production has since recovered and remains high at $54 \%$ of global supply (FAO 2016). In 2017, the global production of farmed shrimp was between 2.93.5 million metric tons, an approximate $6 \%$ increase from 2016. India, Vietnam, and Ecuador continued to be the top 3 exporters of shrimp, while the European Union, United States (US), and Vietnam were leading importers (FAO 2018). 


\subsubsection{U.S. Domestic Importance}

Shrimp in the US is an integral part of the country's food supply, economy, and trade. In 2016 shrimp consumption was 4.1 pounds per capita, while the next closest seafood item was salmon at 2.18 pounds per capita (NOAA 2017b). In that same year, the US landed 132,811 metric tons of shrimp valued at $\$ 522$ million. However, the domestic supply was not nearly enough to satisfy demand. In 2016, 603,543 metric tons of shrimp valued at $\$ 5.7$ billion was imported. Nearly $30 \%$ of all edible seafood imports are that of shrimp products, and domestic shrimp only account for approximately $18 \%$ of total shrimp in the US' supply (NOAA 2017 a, b). The US is the second largest importer of farmed shrimp in the world, and $90 \%$ of shrimp Americans consume is imported (Clark 2014, FAO 2018).

Of the US fishery, the Gulf of Mexico (GOM) alone accounted for $72 \%$ of the country's supply and $79 \%$ of its value, at slightly over $\$ 410$ million, in 2016 , making this region's shrimp the most economically important domestic seafood commodity (NOAA 2017a). The commercial shrimp fishery contributes to coastal economies on many levels. The shrimp value chain is complex consisting of fishermen, dock owners, processors, distributors and consumers (Mine et al. 2016). Aside from the direct sales of shrimp, much of the economic importance of the industry come from maintenance, fuel, supplies and repairs contributing to much of the region's economy (NOAA n.d.).

\subsubsection{Louisiana Importance}

Louisiana has led the US in shrimp landings every year since 2000 and has averaged 43\% of GOM landings since 1963 (Bourgeois et al. 2016). In 2016, Louisiana landed 44,236 metric tons of shrimp valued at over $\$ 135$ million dockside value, 33.3\% 
of the country's and 46\% of the GOM's shrimp (Bourgeois et al. 2016, NOAA 2019). Although shrimp are actually the second largest fishery to menhaden, in Louisiana, they are by far the most valuable. According to Southwick Associates (2008), the shrimp industry contributed an economic value of over $\$ 1.28$ billion to the state in 2006 and provided over 14,000 jobs. Of the 73 different fishery species landed commercially in the state, the four shrimp major species combined (white, brown, pink and seabob) contributed to over half of the state's commercial fisheries jobs and economic value (Southwick Associates 2008).

\subsection{Characterizing the Fishery}

\subsubsection{Species Profile and Biology}

The National Oceanic and Atmospheric Administration (NOAA) reports 6 different species of shrimp landings in Louisiana, however, white shrimp (Litopenaeus setiferus) and brown shrimp (Farfantepenaeus aztecus) are by far the most abundant and valuable (NOAA 2019). These species have very high fecundity with up to one million eggs per spawn and are considered an annual crop making them highly resilient to fishing pressure (Neal and Marris 1985, Bourgeois et al. 2016). Although they can survive for over two years, high fishing and natural mortality severely lowers their average lifespan (Caillouet et al. 2008). Morphologically, white and brown shrimp look very similar. They are distinguished by grooves down both sides of the head and on the last segment of the tail in brown shrimp, which are absent in white shrimp (Tavares 2002). Brown shrimp also have much shorter antennae at about $1.5 x$ body length as opposed to 2.5-3x in white shrimp (Bourgeois et al. 2016). 
As adults both species inhabit similar offshore waters but timing of recruitment into inshore waters varies between species. Brown shrimp eggs typically hatch offshore, and post-larvae move to inshore estuaries between February and April where they feed and mature. They then move offshore to continue to grow and spawn in late spring or summer. White shrimp typically hatch nearshore, and post-larvae migrate further inshore than brown shrimp around May to late summer (O'Connell et al. 2005). White shrimp then move offshore in fall as temperatures cool off (Bourgeois et al. 2016). While post-larvae are inshore they typically prefer mud or vegetated bottoms as the vegetation often protects them from prey (Fry et al. 2003). Once offshore, both species live in deep water with a mud bottom, along the continental shelf (Bourgeois et al. 2016).

Female brown shrimp sexually mature at approximately $140 \mathrm{~mm}$. Males place a spermatophore into the female receptacle where eggs are then released and externally fertilized. Brown shrimp typically produce around 250,000 viable eggs per spawning event. White shrimp females sexually mature at $140 \mathrm{~mm}$ and males mature around $120 \mathrm{~mm}$. Spawning occurs in a similar fashion to brown shrimp, and L. setiferus can spawn up to four times per season. They typically release $0.5-1.0$ million eggs per event (Cook and Lindner 1970, Williams 1984).

Landings for brown and white shrimp vary seasonally. Brown shrimp are usually caught in May and June coinciding with the spring inshore shrimp season. White shrimp are caught mostly in August to October/November coinciding with the fall shrimp season, however according to Sea Grant extension agents there have been an increase in reports of white shrimp during the spring season (Bourgeois et al. 2016). There is an increasing trend in spawning biomass and recruitment, as well as a decreasing trend in 
fishing mortality for both species, indicating neither stock is being overfished (Hart 2012). However, being an annual crop, the strength of each class is highly variable based on survival and distribution of larvae (Caillouet et al. 2008). Environmental factors play the largest role in size of each year class and explain a lot of the variability between yearly landings (Bourgeois et al. 2016). Water temperatures assist in the regulation of spawning and the growth of species. Spikes in temperature often trigger spawning while declines can end the spawning period. Seawater salinity can also play a major role in growth and spawning, which can be affected by weather patterns. Rainfall can lower the salinity of bays and nursery areas, and high rain often lowers both air and water temperatures in late spring and summer, in turn, reducing shrimp size (Muncy 1984).

\subsubsection{Licensing and Permitting}

The commercial shrimp fishery is highly regulated. Specific licenses and permits are required depending on the area fished. State waters occur from the coast out to nine miles while federal waters extend to the exclusive economic zone (EEZ), which is 200 miles offshore. All fishermen in state waters must have a state commercial fishing license, vessel license to operate or own a boat, and gear licenses and permits for each net used. Additional optional licenses include fresh products licenses, wholesale/ retail seafood dealer license, and bait dealer permits. The fresh products license is required for fishermen to sell directly to consumers but requires trip tickets to be filled out and three years of sales data maintained. The wholesale/retail seafood dealer licenses require fishermen to comply with quality and safety regulations (Bourgeois et al. 2016). 
Fishermen in federal waters are required to obtain a shrimp vessel permit from NOAA. They also require a Louisiana Department of Wildlife and Fisheries (LDWF) license if they are landing or docking in Louisiana. From 2000-2013, there was an average of 15,000 gear licenses sold annually in Louisiana. Otter trawl licenses used to be the most popular gear but have since been replaced by skimmer net licenses. Fee sales are another method of tracking the number of fishermen. The number of license holders peaked at over 10,000 individuals in the early 2000's, but has since averaged under 5,600 in the last ten years (Bourgeois et al. 2016). The most recent fisheries data indicate approximately 2,500 resident shrimp trawl licenses, 3,560 resident skimmer nets, and over 600 butterfly nets were sold in 2016 . These permits were held by just under 5,500 fishermen, some of the lowest reported in recent decades. There are currently 379 federal offshore shrimp license holders in Louisiana (LDWF 2018).

\subsubsection{Gear Types}

The primary gear used in the shrimping industry was the otter trawl, which was introduced in 1915 (Klima et al. 1982). In Louisiana, otter trawls accounted for $56 \%$ of shrimp landings between 2000-2013. Skimmer nets produced the second most at approximately 40\% (Bourgeois et al. 2016). The small percentage of shrimp remaining was caught via butterfly and cast nets. Skimmer nets have become more popular in the past few decades as many fishermen have moved inshore to avoid costs associated with offshore fishing. There has also been a moratorium placed on new federal permits, which may contribute to fewer offshore fishermen (Bourgeois et al. 2016).

Federal legislation has tried to prevent the capture of unintended species in trawls. In 1987 the National Marine Fisheries Service required that all trawls above 25 
feet insert Turtle Excluder Devices (TEDs) into their nets (Lewison et al. 2003, Mukherjee and Segerson 2011). Along with TEDs, in 1997 and 1998 trawls fishing in federal waters were required to insert Bycatch Reduction Devices (BRDs) in their nets (Diamond 2004). As a result of these regulations many shrimp fishermen began to use skimmer nets in state waters, which do not require either.

\subsection{Industry in Decline}

\subsubsection{Economic Struggles}

The economic viability of the commercial shrimp industry has changed drastically in the past two decades. When adjusting for inflation, shrimp dockside value in Louisiana has dropped from around $\$ 4.50 / \mathrm{lb}$., in the early 1980 's, to approximately $\$ 1.25 /$ lb. today (Figure 1.1, NOAA 2018).

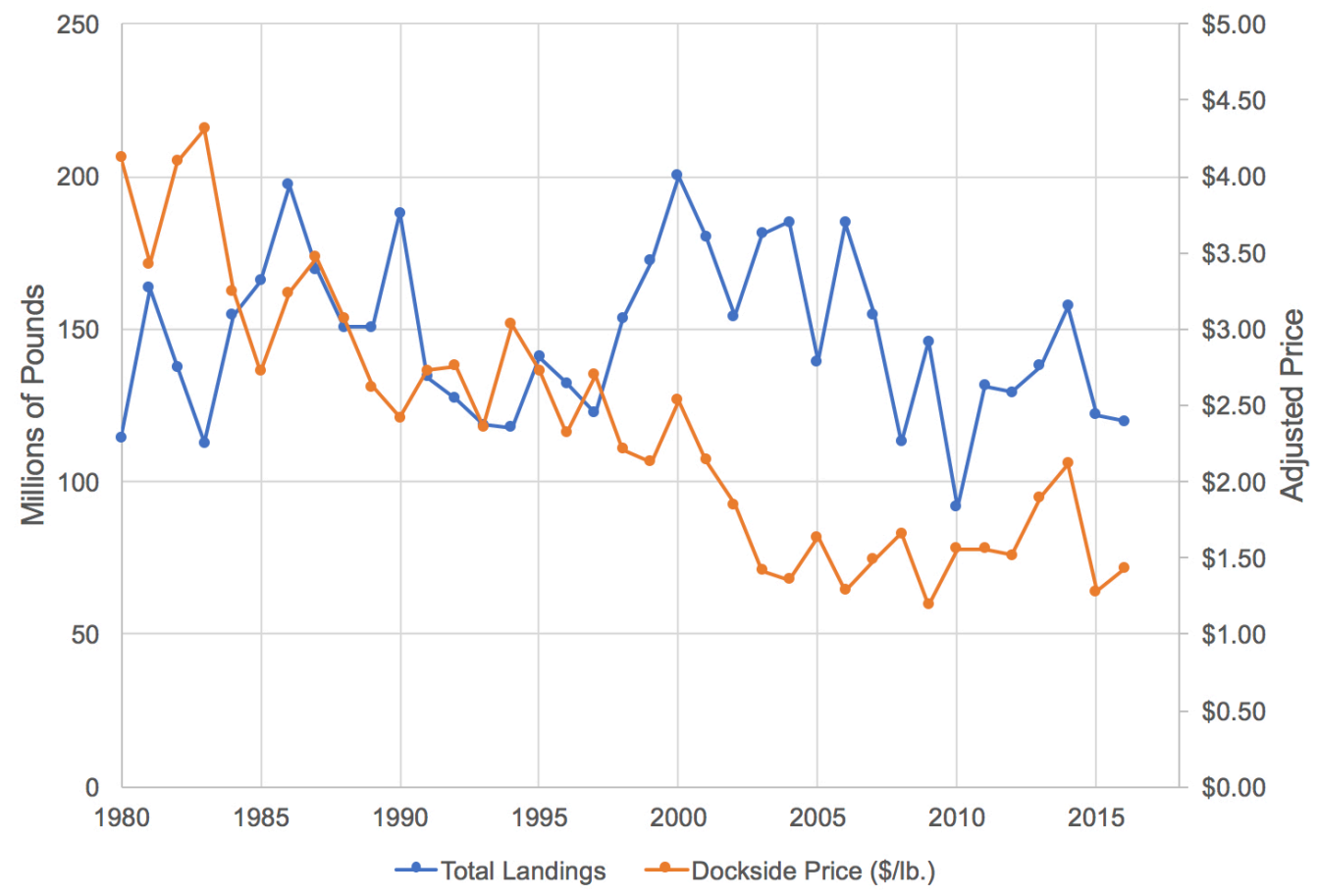

Figure 1.1. Dockside value and landings of Louisiana shrimp from 1980-2016. Dockside value is adjusted to the 2016 U.S. dollar. (Data source: NOAA 2018) 
What used to be a low volume- high profit industry has reversed causing many fishermen to abandon ship, quite literally. Trip costs are often exceeding returns, and increased operating costs followed by declines in market price has caused a cost/ price squeeze forcing downward pressure on fishermen (Tabarestani 2013, NOAA n.d.). There are several factors driving down the price of shrimp that are devastating the industry. The primary causes arise from increased imports into the US, increased operating costs, and negative impacts from supply shocks due to natural disasters.

The greatest threat that commercial shrimp fishermen face today is competition with foreign imports. Due to the inability for domestic production to meet the US' high demand for shrimp, only about $10 \%$ of the country's consumed shrimp is actually caught in the US. Over the past two decades the amount of imports drastically increased forcing strong downward pressure on shrimp prices received dockside (NOAA n.d.). Between 2000 and 2013 imports averaged 1.13 billion pounds to 4.26 billion pounds (Bourgeois et al. 2016). Imports into the US reached record levels at 665,100 metric tons worth over $\$ 6.5$ billion in 2017 (FAO 2018). Dockside prices fell about $40 \%$ between 2000 and 2003 in conjunction with a boom of farmed shrimp imports (Keithly and Poudel 2008, Bourgeois et al. 2016). Increased technology for culturing shrimp along with lower costs have allowed import prices to be very low, which severely lowers dockside price in the US. Changing the tariff structure in 1999 may have redirected more shrimp to the US (NOAA n.d.). Market integration for the shrimp industry suggests that trade restrictions shifts the type of imports as opposed to helping domestic producers (Asche et al. 2012). 
Louisiana's production is not the key factor in driving dockside prices. It is estimated that $76 \%$ of dockside price change is due to import prices (Mine et al. 2016). Louisiana saw high shrimp prices in 2013 and 2014 (Figure 1.1) due to early mortality syndrome devastating the Thailand and other Asian shrimp farms reducing their production by nearly $50 \%$ (Clark 2014, Mine et al. 2016). Other countries began increasing production in response, and eventually, as EMS was controlled, US supply stabilized and prices fell again (Mine et al. 2016).

With shrimp prices declining and operating costs inflating, many shrimp fishermen cannot afford to continue to fish. Aside from increasing fuel, equipment, and repair prices, cost to comply with federal regulations has financially hurt fishermen. The requirement of TEDs and BRDs in the late 1990's caused additional financial burden on the industry (NOAA n.d., Asche et al. 2012). Recent hurricanes have driven up insurance costs, caused coastal erosion, and led to property destruction resulting in a conversion of coastal property from fishing to other alternatives (Caillouet et al. 2008). Hurricanes and other natural disturbances cause alterations to the domestic shrimp market, often negatively impacting US fishermen.

Hurricanes Katrina, Rita, and Wilma in 2005, and the Deepwater Horizon (DWH) oil spill in 2010 , caused severe supply shocks to the domestic shrimp industry. The hurricanes' largest destructive factor arose through devastation of coastal property including many vessels, docks and processors (Buck 2005). DWH impacted the fishery through closures and population disturbances. Research by Duke University investigated the economic viability of the shrimp industry after such severe supply shocks. The level of market integration between wild caught shrimp and farmed shrimp, 
determines how supply shocks are mediated. Based on their research, supply shocks do not cause prices to rise, rather imports of foreign farm raised shrimp increase (Asche et al. 2012).

The effects of hypoxia on the shrimp market have also been analyzed. The Mississippi-Atchafalaya basin river system is one of the largest in the world and drains $41 \%$ of continental US resulting in a large hypoxic zone off Louisiana's coast (Craig 2012). It is believed that the effect of hypoxia in the GOM has been masked by the previous, larger supply shocks. Shrimp fishing in Louisiana peaks in summer when hypoxia is most severe, and landings and effort tend to be low in hypoxic areas around the continental shelf (Craig 2012). There is also evidence that hypoxia in the GOM decreases the supply of large shrimp and increases the smaller shrimp supply (Craig 2012). Since shrimp prices are directly correlated with size, and larger shrimp fetch higher prices, this can cause an even greater reduction of value. Market integration also suggests that decreased supply of larger shrimp will not be offset by higher prices, rather more larger count shrimp will be imported (Asche et al. 2012). In face of these economic issues fishermen face, the industry is declining rapidly.

\subsubsection{Historical Decline in Effort}

A massive decline in shrimp fishing effort has been observed over time. Between 1960 and 1989, estimated fishing effort increased greatly. Total effort increased approximately 2.5 times from 124,000 days at sea to 301,000 days in the 30 -year study period (Nance 1992). However, between 2002 and 2011, fishing effort declined from over 162,000 days to a mere 54,000 days in the white shrimp fishery. Despite the declining effort, catch per unit effort (CPUE) has been steadily increasing (Hart and 
Nance 2013). Severe industry decline has also been reported through license sales. Gear fee sales data indicates the number of licensed shrimp fishermen, in LA, has declined nearly $50 \%$ from 2001 to 2008 . The number of fishermen reporting trip tickets also declined from 7,000 to 2,912 in those same years. The largest sector of the fishery that has been affected are the day boat fishermen, who fish nearshore and for shorter intervals. The number of trips lasting less than 24 hours declined by nearly $70 \%$ from 2000 to 2013 (Bourgeois et al. 2016). Record high operating costs followed by record low dockside values have driven more than half of the state's fishermen out of the industry. Strategies to increase value for fishermen's product are being explored as a solution to the rapidly declining industry.

\subsubsection{Efforts to Increase Price}

The value chain in the shrimp market is complex as markup occurs from vessel to dockside to processors and eventually to wholesale distributors and retailers. It is not uncommon for vessels to receive less than $\$ 2$ per pound for shrimp while grocery stores and restaurants sell the same product for up to 10x that same price (Mine et al. 2016).

Programs and partnerships like Louisiana Direct Seafood, Louisiana Fisheries Forward by Louisiana Sea Grant and Louisiana State University Agricultural Center are working extensively towards increasing price for domestic shrimp by changing the supply line and improving quality. Overall, the goal of these efforts is to separate out Louisiana shrimp from the international shrimp commodity market. There are several recommendations to increase price for fishermen, often by skipping steps in the value chain. Selling more product directly to consumers gives harvesters an opportunity to increase the value of their shrimp (Mine et al. 2016). While LDWF offers optional 
licenses making it possible to distribute directly to consumers, a decline in these license sales has been seen. Fresh products license holders declined from 339 licensees selling over 300,000 pounds of shrimp in 2010 to only 168 selling 57,000 pounds in 2013 (Bourgeois et al. 2016). However, selling direct is possible for more shrimp fishermen. Through the development of the Louisiana Direct Seafood program between 150 and 200 shrimpers in the state now sell their product using a direct seafood market or social media (Mine et al. 2016). Value-added shrimp products can increase price by volume, and these efforts can be combined with direct marketing to greatly increase economic output. Sea Grant uses a mobile seafood quality training lab to demonstrate best practices in handling and packaging techniques to shrimpers, restaurants and consumers (T. Hymel, pers. comm.). For example, Vermillion Bay Sweet is a valueadded brand run by the Port of Delcambre, LA, that began with peeled, vacuum packed shrimp in one pound bags that are convenient for the average consumer to buy and cook at home.

\subsection{Consumer Quality and Awareness}

\subsubsection{Cold Chain Management}

Wild caught shrimp are often preferred by consumers due to their superior flavor and texture (Brayden et al. 2018). In an industry where quality is variable and the product is seasonal, improving freezing techniques and standard operating procedures can increase value of shrimp. The ability to store and hold frozen product is the greatest advantage wholesalers have over fishermen and docks as they can selectively choose when and where to sell and distribute shrimp. Currently, most shrimp fishermen sell directly to a dock or processor where they are often forced to accept low prices. 
Improved freezing technology that allows fishermen to bypass steps in the market chain and sell direct can help enhance the economic viability and resiliency of the industry.

The cold chain management process is crucial to the final quality in shrimp. The faster shrimp are chilled and frozen, the higher quality they typically will be (Fieger and Friloux 1954). There are several different methods of freezing shrimp, and the higher quality methods can fetch more money per unit shrimp (Mine et al. 2016). The traditional and most popular method of storing catch on board is through the use of ice holds. After being caught shrimp are thrown on ice and covered up until the boat gets back to a dock. This process can cause shrimp to stay chilled on ice for several days or possibly up to a week (J, Lively, pers. comm.). A 1952 study on Gulf brown shrimp concluded that the longer shrimp are stored on ice, prior to freezing, the lower the shelf life and quality the product will be (Fieger and Friloux 1954). Many fishermen have switched to brine freezing systems onboard their ships. There are an estimated 300 larger offshore vessels that have brine freezing, also known as individual quick freezing (IQF), systems that can individually freeze shrimp in 20 minutes. These systems can cost anywhere from $\$ 21,000-55,000$ to install onboard (Mine et al. 2016). Despite quickly freezing shrimp, the brine solution and subsequent handling often causes the incidental removal of appendages ( $T$, Hymel, pers. comm.). Loss of appendages can result in a higher percentage of unusable shrimp for high-end restaurants that serve whole, head-on shrimp dishes.

Newer technology is developing and becoming more popular to maintain high quality. Recirculated chilled water systems use seawater for mechanical refrigeration and a pump system to keep shrimp cold, and an estimated 25 vessels have these 
systems (Mine et al. 2016). The use of plate freezers onboard fishing vessels is common in other fisheries and is considered one of better available methods for freezing catch (Kolbe 2004, Ruiz et al. 2012). Shrimp that are chilled and plate frozen quickly onboard are often considered the most valuable shrimp product on the market ( $T$, Hymel, pers. comm.). These systems cost between $\$ 20,000-\$ 25,000$ to install but can be installed on much smaller vessels than the IQF systems. Only an estimated 10 Louisiana shrimp fisherman utilize plate freezing technology (Mine et al. 2016). Plate freezers installed onboard ships and dockside have the potential to give fishermen the increased price typically received by wholesalers and show promise to a struggling industry. However, the equipment must be used correctly and quality maintained throughout other processing steps.

\subsubsection{Quality Determination and Consistency}

Maintaining the highest quality shrimp is essential in order to fetch top dollar for the product. The United States Department of Commerce (USDC) and NOAA Seafood Commerce's seafood inspection manual provides guidelines to what is considered high quality in shrimp and how to test for those variables. The goal for most suppliers is to have grade A shrimp products, the best by USDC standards. This means that the shrimp possess good flavor and odor characteristics and comply with the limit for defects. Qualitative variables commonly examined to grade shrimp are the uniformity in size count, black spot development, counting broken and damaged shrimp, unusable material, unacceptable shrimp, or inadvertently peeled shrimp. Quantitative variables that can be measured are the dehydration of the shrimp (i.e. moisture content), salt content, and bacterial levels (USDC 2011). Shrimp are classified by the number of 
shrimp per pound, which is referred to as their size count and is generally given as a range. Larger shrimp, which are identified by a smaller size count, are considered more valuable and almost always produce a higher price per pound than smaller shrimp.

Consistency in quality is an issue as quality is directly related to operating procedures. Microbiological assessment of shrimp for Aerobic Plate Count (APC) and total coliforms can reveal the quality of a product prior to freezing. Fish and shellfish typically have fairly low bacterial counts when caught, however levels can spike significantly in the time between catch and freezing (Swartzentruber et al. 1980). Fieger and Friloux (1954) also concluded that high variability in bacterial plate counts likely indicated poor quality at the time of handling or packaging. These studies stress the importance of proper handling techniques to ensure great quality.

Handling procedures can also impact the appearance and chemical composition of shrimp. Imported farmed shrimp may contain antibiotic residue that could be harmful to consumers, however this is not a major problem for wild caught shrimp (Pham et al. 2015). Residual sulfite in shrimp tissue is a more common issue seen in the commercial shrimp fishing industry. Sulfite, or metabisulfite, products are commonly used to inhibit the development of black spot or melanosis on shrimp.

\subsubsection{Melanosis and Black Spot Development}

Melanosis, also known as black spot, is the development of black pigments on the exoskeletons of crustaceans postmortem (Montero et al. 2004). On shrimp, black spots typically begin on the cephalothorax and caudal tip of the tail, before spreading to the rest of the shell. Although melanosis is not harmful and does not lower the quality or taste of shrimp, it is a huge issue in the marketing of product as it leads to consumer 
rejection (Lopez-Caballero et al. 2000, Montero et al. 2004). The development typically begins within hours of refrigeration and freezing then continues through post-freeze thawing (lyengar et al. 1991, Montero et al. 2004). The activation of the pigments is caused by polyphenoloxidase (PPO) which is an enzyme that oxidizes phenols to quinones. The polymerization of quinones then leads to the development of black spots. The enzyme remains active during refrigeration and thawing as the presence of oxygen is needed for the process to occur (Montero et al. 2004). The inhibition of melanosis development is a vital aspect for processing shrimp post catch. Black spot is not harmful or indicative of spoilage. However, excess black spot can lead to USDC deductions for quality (USDC 2011).

There are several substances that can be used to inhibit black spot, however application of sulfite products to shrimp is traditionally used in the industry. Sulfites, including metabisulfites, are sulfur based compounds containing the sulfite ion $\mathrm{SO}_{3}{ }^{(2-)}$ and have been frequently used in food preservation (Gomez-Guillen et al. 2005, GarciaGavin et al. 2012). Sulfite formulas work in two ways to inhibit melanosis: reacting with intermediate quinones to form sulfoquinones and reversibly reacting with PPO for complete inactivation (Ferrer et al. 1989). Application of these products typically occurs on board after harvest via a dipping procedure. Despite their effectiveness in the shrimp market, sulfites can be a trigger for people with asthma and cause allergic reactions in consumers sensitive to sulfur based products (Collins-Williams 1983). Results from a study by Gomez-Guillen et al. (2005) found that the dusting method of application, instead of dipping, leads to higher residual sulfite levels in shrimp muscle tissue (Gomez-Guillen et al. 2005). Sulfite levels in food are federally regulated and cannot 
exceed 100 ppm (FDA 2001). Residual levels can be quickly tested in shrimp products with a simple dye test. Sulfite sensitive asthmatics do not always react to sulfite ingestion; reactions depend on food type, residual levels and consumer sensitivity (Taylor et al. 1988). Perhaps the most dangerous use of sulfites come from safety hazards in application. Sulfites are unstable and form sulfur dioxide when reacting with water, which has led to deaths in shrimp holds on rare occasions (lyengar et al. 1991). Contact dermatitis resulting from sodium metabisulfites was also found to be frequent and often relevant in patch-tested patients (Garvia-Gavin et al. 2012). One final issue with sulfite use is that they have the potential to bleach black spot out of shrimp. While promoted as an advantage, it encourages the excessive use of product leading to residual levels above federal standards (lyengar et al. 1991, Montero et al. 2004). These hazards are leading to increased research and use of alternative methods to control black spot formation.

The most common alternative to sulfites today is the use of 4-hexylresorcinol (4HR). Several commercial products on the market, (i.e. Prawnfresh ${ }^{\mathrm{TM}}$ and EverFresh $®$ ), can be effectively used on shrimp boats to delay the onset of melanosis. There are many reasons why 4-HR is a better option than sulfite. First, the potential for excess use is very small compared to sulfites. Recommended sulfite concentration use is 250 times greater than products such as EverFresh ${ }^{\circledR}$. They also do not bleach out black spot after it has developed, thus there is no encouragement for excess use as functionality does not increase (lyengar et al. 1991). Second, it is much safer than metabisulfites. 4-HR is a stable compound and effective at much lower concentrations leading to little or no residual compound in shrimp muscle tissue. Finally, it has proven to be even more 
effective than sulfites; effectively delaying melanosis for up to 14 days (Otwell et al. 1992). 4-HR was found to be effective at extending shelf life of shrimp at all concentrations tested from $0.225 \%-1.0 \%$ (Montero et al. 2004). EverFresh $\circledast$ and Prawnfresh ${ }^{\mathrm{TM}}$ delayed the onset of melanosis for up to 12 days while sulfite dipped shrimp were found to be unacceptable after 2-4 days (Lively, unpublished). The standard operating procedure for shrimping does not need to be adjusted for the switch; application of a 4-HR formula is a simple change from sulfite to alternative formulas in the chill or dip tank. Although traditional methods of processing are able to be used for 4-HR, new packaging techniques are being investigated to determine other potential solutions to the spoilage of shrimp.

Lopez-Caballero et al. (2000) tested the effectiveness of vacuum packaging and high-pressure packaging on prawn tails. They found that the control batch of shrimp stored at $3{ }^{\circ} \mathrm{C}$ were found unacceptable after 3 days based on the black spot scale, while vacuum packaging successfully inhibited black spot for 35 days in tiger prawns (Lopez-Caballero et al. 2000). Despite their relative success, mixed results have been found for vacuum packaging. When testing vacuum packaging and modified atmosphere packaging (MAP), the combination of vacuum packaging and frozen storage did not effectively delay black spot development on deepwater rose shrimp. This could be due to a trace amount of oxygen between shrimp that could not be removed causing the continued activation of enzymes responsible for pigment development (Bono et al. 2012). However, results from modified atmosphere packs showed that when packaged with $100 \% \mathrm{~N}_{2}$, color was maintained for up to 6 months in 
frozen packed shrimp (Bono et al. 2012). MAP may not be a realistic solution for melanosis inhibition in shrimp as equipment costs are very high.

\subsubsection{Bycatch and Ecofriendly Catch}

Bycatch, which is considered discarded catch due to economic or regulatory reasons, is a major issue in the shrimp fishery. Trawling is one of the least selective gear types and provides many economic and ethical issues associated with mortality of bycatch and destruction of habitat (Diamond 2004). There is a great concern for trawling's effect on threatened, endangered and protected species. In the GOM specifically, sea turtles and juvenile red snapper bycatch have historically been species of concern by regulators. TEDs have significantly reduced the amount of turtle mortality in otter trawls, with some estimates reporting a 71\% reduction in turtle mortality (Epperly et al. 2002). Finfish mortality reduction has not been as successful. It was reported in 2000 that an estimated 25-30 million juvenile red snapper were caught annually as bycatch (Ortiz et al. 2000). Red snapper are an extremely popular recreational fish and are still a large concern for shrimp trawl bycatch. BRDs were required in 1998 in trawls fishing in federal waters, but have provided only minimal reduction in finfish mortality (Diamond 2004). In the past couple decades, the addition of BRDs and TEDs have reduced bycatch to some extent. From 2007-2010 observers on boats with BRDs reported a bycatch to shrimp ratio of $2.5: 1 \mathrm{~kg}$, however finfish accounted for nearly $57 \%$ of total catch (Pulver et al. 2012). The largest percentage of the Louisiana fishery is comprised of skimmer nets (Bourgeois et al. 2016), which produce significantly reduced bycatch compared to otter trawls (Scott-Denton et al. 2006), with ratios some years as low at $0.92: 1 \mathrm{~kg}$ (Pulver et al. 2014). Average bycatch ratios are typically derived from 
voluntary observer programs and fluctuate yearly based on several factors including gear type, season, BRD use, and other variables.

According to preliminary data in a study of the Texas blue crab fishery, abundance of crabs caught in shrimp trawls increased by $83 \%$ to approximately 80 million crabs from 1982-1994 (Hammerschmidt et al. 1998). Based on bycatch weights and composition, it is also estimated that over 20 million pounds of blue crabs are captured in Louisiana per year (Adkins 1993). The exact number of blue crabs captured in shrimp gear is unknown. However, due to many juvenile and immature crabs being released it is assumed that the actual number exceeds that harvested by commercial crab fishermen. Towing and bycatch separation procedures may have significant impacts on blue crab survival through physical damage and delayed mortality due to stress (Guillory 2001).

\subsection{Significance and Objectives}

Louisiana commercial shrimp fishermen have overcome extreme adversity, yet many have been forced out of the industry. In the face of foreign imports, destructive hurricanes and oil spills, and increasing operating costs, shrimp fishermen are making less money than ever before. The industry is vital to the state as it contributed over 14,000 jobs and over 1.2-billion-dollar total economic effect in 2006 (Southwick Associates 2008). Despite successful efforts from Louisiana Sea Grant and Louisiana State University Agricultural Center in adding value to the dying industry, there is much work to do. Pressure from foreign countries is unlikely to halt as shrimp imports are increasing. Technological advancements, such as contact plate freezers, in postharvest processes could contribute to an improved future for the industry. The ability to 
market a premium quality, sulfite-free shrimp product to restaurants throughout the state can improve the economic well-being of fishermen. Development of dockside platefreezing has the potential to enhance the quality of Louisiana shrimp and provide opportunity to those with smaller vessels.

The central goal of this project is to determine best practices in post-harvest procedures to improve economic value and resiliency of the Louisiana commercial shrimping industry. Louisiana Sea Grant has been remarkable in their efforts to increase the value of Louisiana shrimp through programs and partnerships providing fishermen with direct marketing opportunities. With their continued assistance, this project provides advice and scientific data to back the development of a trademarked plate frozen brand: Louisiana Limited Wild Plate Frozen Shrimp (LLWPFS), a voluntary program for fishermen to improve the economic value and quality of their product. The brand was created by Louisiana Sea Grant, and participants using the trademarked logo must use best management practices and follow a developed standard operating procedure that is defined through this research. The program will be owned and policed by the Port of Delcambre, LA to ensure standards are being upheld. Plate freezing entities can buy into the program, upon signing a contract with the Port, to use the LLWPFS logo on their product. The market and product preferences will be established through surveys of chefs, restaurant owners, and managers. A preliminary survey on plate frozen shrimp found that under half of New Orleans chefs had heard of shrimp being plate frozen and only a few had used it (Lively, Unpublished). This research investigates the potential of plate freezing technology to improve the resiliency of the shrimp industry by examining all processes from fishing to distribution. 
In order to assist with the development of this program, my objectives were to: 1) Observationally determine best practices via onboard data collection with plate freezing entities, 2) Establish a market and determine product preferences for plate frozen shrimp through surveys of chefs, restaurant owners, and managers, 3) Experimentally determine optimal melanosis inhibition procedures, 4) Assess the quality of plate frozen shrimp, 5) Analyze the effect of saltbox use on blue crab mortality, and 6) Determine the effect of saltbox salinity on culling efficiency.

\subsection{References}

Adkins, G. 1993. A comprehensive assessment of bycatch in the Louisiana shrimp fishery. Louisiana Department of Wildlife and Fisheries. Technical Bulletin 42:71.

Arquitt, S., X. Honggang, and R. Johnstone. 2005. A system dynamics analysis of boom and bust in the shrimp aquaculture industry. System Dynamics Review: The Journal of the System Dynamics Society 21(4):305-324.

Asche, F., L. S. Bennear, A. Oglend, and M. D. Smith. 2012. US shrimp market integration. Marine resource economics 27(2):181-192.

Bono, G., C. V. Badalucco, S. Cusumano, and G. B. Palmegiano. 2012. Toward shrimp without chemical additives: A combined freezing-MAP approach. LWT-Food Science and Technology 46(1):274-279.

Bourgeois, M., K. Chapiesky, L. Landy., J. Lightner, J. Marx. 2016. Louisiana Shrimp, in Fishery Management Plan; Louisiana Department of Wildlife and Fisheries: Baton Rouge, LA; pp 1-158.

Brayden, W. C., C. L. Noblet, K. S. Evans, and L. Rickard. 2018. Consumer preferences for seafood attributes of wild-harvested and farm-raised products. Aquaculture Economics \& Management 22(3):362-382.

Buck, E. H. 2005. Hurricanes Katrina and Rita: Fishing and Aquaculture Industries-Damage and Recovery. Congressional Research Service, Library of Congress.

Caillouet Jr, C., R. Hart, and J. Nance. 2008. Growth overfishing in the brown shrimp fishery of Texas, Louisiana, and adjoining Gulf of Mexico EEZ. Fisheries Research 92(2-3):289-302.

Clark, B. H. 2014. More than one-third of U.S. shrimp may be mislabeled, study says. National Geographic. Retrieved December 2017 from 


\section{http://news.nationalgeographic.com/news/2014/10/141030-shrimp-mislabeling-}

seafood- fraud-oceana-food/

Collins-Williams, C. 1983. Intolerance to additives. Annals of allergy 51(2 Pt 2):315.

Cook, H. L., and M. J. Lindner. 1970. Synopsis of biological data on the brown shrimp, Penaeus aztecus Ives, 1891.

Craig, J. K. 2012. Aggregation on the edge: effects of hypoxia avoidance on the spatial distribution of brown shrimp and demersal fishes in the Northern Gulf of Mexico. Marine Ecology Progress Series 445:75-95.

Diamond, S. L. 2004. Bycatch quotas in the Gulf of Mexico shrimp trawl fishery: can they work? Reviews in Fish Biology and Fisheries 14(2):207-237.

Epperly, S., L. Avens, L. Garrison, T. Henwood, W. Hoggard, J. Mitchell, J. Nance, J. Poffenberger, C. Sasso, and E. Scott-Denton. 2002. Analysis of sea turtle bycatch in the commercial shrimp fisheries of southeast US waters and the Gulf of Mexico.

Ferrer, O. J., J. A. Koburger, W. S. Otwell, R. A. Gleeson, B. K. Simpson, and M. R. Marshall. 1989. Phenoloxidase from the cuticle of Florida spiny lobster (Panulirus argus): Mode of activation and characterization. Journal of Food Science 54(1):63-67.

Fieger, E., and J. Friloux. 1954. Comparison of objective tests for quality of fresh and frozen Gulf shrimp.

Food and Agricultural Organization (FAO). 2009. The State of World Fisheries and Aquaculture 2008. Rome.

Food and Agricultural Organization (FAO). 2016. The State of World Fisheries and Aquaculture 2016. Contributing to food security and nutrition for all. Rome. 200 pp.

Food and Agricultural Organization (FAO). 2018. Globefish Highlights - A Quarterly Update on World Seafood Markets. April 2018 issue, with Annual 2017 Statistics.

Food and Drug Administration (FDA). 2001. Food \& Color Additives. Ch. 19. In Fish and Fishery Products Hazards and Controls Guidance, 3rd ed., p. 237-248. Food and Drug Administration, Center for Food Safety and Applied Nutrition, Office of Seafood, Washington, DC.

Fry, B., D. M. Baltz, M. C. Benfield, J. W. Fleeger, A. Gace, H. L. Haas, and Z. J. Quiñones-Rivera. 2003. Stable isotope indicators of movement and residency for brown shrimp (Farfantepenaeus aztecus) in coastal Louisiana marshscapes. Estuaries 26(1):82-97. 
García-Gavín, J., J. Parente, and A. Goossens. 2012. Allergic contact dermatitis caused by sodium metabisulfite: a challenging allergen. A case series and literature review. Contact Dermatitis 67(5):260-269.

Gómez-Guillén, M. C., Ó. Martínez-Alvarez, A. Llamas, and P. Montero. 2005. Melanosis inhibition and SO2 residual levels in shrimps (Parapenaeus longirostris) after different sulfite-based treatments. Journal of the Science of Food and Agriculture 85(7):1143-1148.

Guillory, V. 2001. A review of incidental fishing mortalities of blue crabs. Pages $28-41$ in Proceedings of the blue crab mortality symposium.

Hammerschmidt, P., T. Wagner, and G. Lewis. 1998. II. State Blue Crab FisheriesTexas to New York-Status and trends in the Texas blue crab (Callinectes sapidus) fishery. Journal of Shellfish Research 17(2):405-412.

Hart, R. A. 2012. Stock assessment of brown shrimp (Farfantepenaeus aztecus) in the US Gulf of Mexico for 2011.

Hart, R. A., and J. M. Nance. 2013. Three decades of US Gulf of Mexico white shrimp, Litopenaeus setiferus, commercial catch statistics. Marine Fisheries Review 75(4):43-47.

lyengar, R., C. W. Bohmont, and A. J. Mcevily. 1991. 4-Hexylresorcinol and prevention of shrimp blackspot: residual analyses. Journal of food composition and analysis 4(2):148-157.

Keithly Jr, W. R., and P. Poudel. 2008. The Southeast USA shrimp industry: issues related to trade and antidumping duties. Marine resource economics 23(4):459483.

Kolbe, E. R. 2004. Chilling and freezing guidelines to maintain onboard quality and safety of Albacore tuna.

Klima, E. F., K. N. Baxter, and F. Patella. 1982. A review of the offshore shrimp fishery and the 1981 Texas closure.

Lewison, R. L., L. B. Crowder, and D. J. Shaver. 2003. The impact of turtle excluder devices and fisheries closures on loggerhead and Kemp's ridley strandings in the western Gulf of Mexico. Conservation Biology 17(4):1089-1097.

López-Caballero, M., M. Pérez-Mateos, J. Borderias, and P. Montero. 2000. Extension of the shelf life of prawns (Penaeus japonicus) by vacuum packaging and highpressure treatment. Journal of food protection 63(10):1381-1388. 
Louisiana Department of Wildlife and Fisheries. 2018. Commercial License Sales 2016. Retrieved June 2018 from http://www.wlf.louisiana.gov/licenses/statistics.

Mine, S., R. Chen, S. Shelby, M. Lowe. 2016. Louisiana Shrimp Value Chain: Price Dynamics, Challenges and Opportunities. Datu Research. October 2016.

Montero, P., O. Martínez-Álvarez, and M. D. C. Gómez-Guillén. 2004. Effectiveness of onboard application of 4-hexylresorcinol in inhibiting melanosis in shrimp (Parapenaeus longirostris). Journal of Food Science 69(8):C643-C647.

Mukherjee, Z., and K. Segerson. 2011. Turtle excluder device regulation and shrimp harvest: the role of behavioral and market responses. Marine resource economics 26(3):173-189.

Muncy, R. J. 1984. Species Profiles. Life Histories and Environmental Requirements of Coastal Fishes and Invertebrates (Gulf of Mexico). White Shrimp. Mississippi Cooperative Fish and Wildlife Unit. Mississippi State.

Nance, J. M. 1992. Estimation of effort for the Gulf of Mexico shrimp fishery.

National Oceanic and Atmospheric Administration- Fisheries. NOAA n.d. Retrieved November 2017 from http://www.nmfs.noaa.gov/mediacenter/fish_files/EShrimpBusinessOptions.pdf

National Oceanic and Atmospheric Administration - National Marine Fisheries Service. 2017a. Imports and Exports of Fishery Products Annual Summary, 2016.

National Oceanic and Atmospheric Administration - National Marine Fisheries ServiceOffice of Science and Technology. 2017b. Fisheries of the United States, 2016.

National Oceanic and Atmospheric Administration - National Marine Fisheries Service. 2018. Commercial Fisheries Statistics. Retrieved June 2018 from https://www.st.nmfs.noaa.gov/commercial-fisheries/commercial-landings/annuallandings/index.

National Oceanic and Atmospheric Administration - National Marine Fisheries Service. 2019. Annual Commercial Landings Statistics. Retrieved May 2019 from https://www.st.nmfs.noaa.gov/commercial-fisheries/commerciallandings/annuallandings/index.

Neal, R. A., and R. C. Maris. 1985. Fisheries biology of shrimps and shrimplike animals. Economic aspects: fisheries and culture 10:1-110.

O'Connell, M. T., C. D. Franze, E. A. Spalding, and M. A. Poirrier. 2005. Biological resources of the Louisiana coast: part 2. Coastal animals and habitat associations. Journal of Coastal Research:146-161. 
Ortiz, M., C. M. Legault, and N. M. Ehrhardt. 2000. An alternative method for estimating bycatch from the US shrimp trawl fishery in the Gulf of Mexico, 1972-1995.

Fishery Bulletin 98(3):583-583.

Otwell, W. S., R. lyengar, and A. J. McEvily. 1992. Inhibition of shrimp melanosis by 4hexylresorcinol. Journal of Aquatic Food Product Technology 1(1):53-65.

Pham, D. K., and coauthors. 2015. Monitoring antibiotic use and residue in freshwater aquaculture for domestic use in Vietnam. EcoHealth 12(3):480-489.

Pulver, J. R., E. Scott-Denton, and J. A. Williams. 2012. Characterization of the US Gulf of Mexico skimmer trawl fishery based on observer data.

Pulver, J. R., E. Scott-Denton, and J. A. Williams. 2014. Observer coverage of the 2013 Gulf of Mexico skimmer trawl fishery.

Ruiz, V. 2012. Analysis of existing refrigeration plants onboard fishing vessels and improvement possibilities. Second International Symposium on fishing vessel Energy Efficiency.

Scott-Denton, E., and coauthors. 2006. Skimmer trawl fishery catch evaluations in coastal Louisiana, 2004 and 2005. Marine Fisheries Review 68(1-4):30-35.

Southwick Associates. 2008. The economic benefits of fisheries, wildlife, and boating resources in the state of Louisiana. Department of Wildlife and Fisheries, Office of Management and Finance.

Swartzentruber, A., A. Schwab, A. Duran, B. Wentz, and R. Read. 1980. Microbiological quality of frozen shrimp and lobster tail in the retail market. Appl. Environ. Microbiol. 40(4):765-769.

Tabarestani, M. 2013. The effects of US shrimp imports on the Gulf of Mexico dockside price: a source differentiated mixed demand model.

Taylor, S. L., and coauthors. 1988. Sensitivity to sulfited foods among sulfite-sensitive subjects with asthma. Journal of allergy and clinical immunology 81(6):11591167.

Tavares, M. 2002. Shrimps. In: W. Fischer, editor. FAO species identification sheets for fishery purposes: Western Central Atlantic (Fishing Area 31). FAO, Rome, pp. 251-291.

Williams, A. B. 1984. Shrimps, lobsters, and crabs of the Atlantic coast of the eastern United States, Maine to Florida. 


\section{CHAPTER 2. LOUISIANA LIMITED WILD PLATE FROZEN SHRIMP}

\subsection{Introduction}

Shrimp are an extremely important resource economically and culturally to the United States (US). In 2017, the US harvested over 133 metric tons of wild caught shrimp, valued at over $\$ 555$ million (NOAA 2019). The Gulf of Mexico (GOM) waters accounted for $78 \%$ of that catch and over $80 \%$ of the value, making this region the primary source of US shrimp. Louisiana contributes more shrimp to the domestic market than any other state in the country at approximately $32 \%$ of total landings and $25 \%$ of its value (NOAA 2019). Competition with foreign imports has negatively affected the industry and is driving down dockside value in the US (Asche et al. 2012). Dockside value of shrimp has declined over 30\% from the 90's to 2000's in the GOM (Tabarestani et al. 2017), and $40 \%$ between the years 2000 and 2003 alone for the southeastern US (Keithly and Poudel 2008). Deflated dockside price reached heights of over $\$ 4$ per pound historically, yet today fishermen in Louisiana often receive less than $\$ 1.50$ per pound (Figure 1.1). This decline has been associated with a boom in foreign shrimp aquaculture production and an influx of imported shrimp (Asche et al. 2012). The US is currently the second largest importer of shrimp in the world, and imports continue to rise, as there was a $6 \%$ increase from 2016-2017 (FAO 2018). Low prices have driven commercial shrimp fishermen out of the industry. There are less than $50 \%$ of Louisiana commercial shrimp fishermen today than there was two decades ago (Bourgeois et al. 2016).

Efforts to increase value in the industry are of great interest to organizations in Louisiana. Most shrimp fishermen follow traditional business plans where they sell their 
catch directly to a dock after fishing. This method provides little leeway for negotiation, and shrimpers are often forced to sell at low prices. The ability to freeze and store catch for periods of time gives processors a seasonal advantage to hold onto product longer and sell to proper markets at inflated prices. Some fishermen have taken advantage of newer freezing technology, such as individually quick frozen (IQF) systems, which use a brine solution to freeze sacks of shrimp (Mine et al. 2016). These systems are large, expensive and not a viable option for many fishermen, as more than half of the industry is comprised of smaller skimmer boats (Bourgeois et al. 2016). The brine solution can also lead to appendage loss, deteriorating the quality of whole shrimp (T. Hymel, pers. comm.). Newer plate freezing technology has been used in other fisheries across the globe (Kolbe 2004, Ruiz et al. 2012), but has not been adopted by many in the GOM. The installation of plate freezers is expensive but can be achieved on much smaller vessels, including skimmer boats (Mine et al. 2016). The quality of shrimp frozen using plate freezing equipment is considered the highest as shrimp are flash frozen at $-40{ }^{\circ} \mathrm{C}$ within hours of catch. Shrimp retain all appendages and natural color through freezing, creating a visually appealing product ( $T$. Hymel pers. comm.).

Improving shrimp quality can also increase product value. Wild caught shrimp are often preferred by consumers (Brayden et al. 2018) and typically lack harmful drug residue and bacteria found in some imported shrimp (Pham et al. 2015, Khan 2018). Shrimp quality is determined through the cold chain management process and handling procedures (Fieger and Friloux 1954). Variability in storage temperatures can determine the shelf life and rates of deterioration of shrimp (Tsironi et al. 2009). The goal for improved quality is to lower the internal temperature of shrimp as fast as possible. 
Treatment of shrimp with additives to prevent spoilage or consumer rejection can also affect quality. Shrimp develop black spots, or melanosis, naturally post-mortem, and the inhibition of melanosis is of particular interest to improve quality.

Sulfite products are traditionally used in commercial shrimp fisheries to inhibit the development of melanosis. Melanosis is not harmful to consumers but often leads to consumer rejection (Lopez-Caballero et al. 2000). Sulfites are often a trigger for asthmatics and cause allergic reactions in sulfite-sensitive individuals. Moving away from traditional sulfite use to safer, more effective products is a goal for improved quality. 4-Hexylresorcinol (4-HR) products, such as EverFresh ${ }^{\circledR}$ and Prawnfresh ${ }^{\mathrm{TM}}$, have been found to significantly inhibit the development of black spot (Otwell et al. 1992, Montero et al. 2004, Lively, unpublished). Different packaging methods have shown mixed effects in reducing black spot. Vacuum-packaging and Modified Atmosphere Packaging (MAP), which alters the atmospheric gases in the package, have been found effective in various studies (Lopez-Caballero et al. 2000, Bono et al. 2012). Determining the best post-harvest procedures for melanosis inhibition is essential for a consistent, high quality product.

Louisiana Sea Grant partnered with fishermen to create a Louisiana Direct Seafood market and website, as well as established dockside markets across the state (T Hymel, pers. comm.). Markets provide opportunity for fishermen to sell directly to the public and earn more profit for their products, by skipping steps in the value chain (Mine et al. 2016). Most recently, Louisiana Sea Grant has developed a logoed product to identify improved quality and increase value for Louisiana shrimp fishermen. 
Louisiana Limited Wild Plate Frozen Shrimp (LLWPFS) brand has been established to consistently fetch top dollar from consumers. The logo is owned and operated through the Port of Delcambre in Iberia and Vermillion Parishes of Louisiana. In collaboration with several shrimp fishermen using plate freezing technology, an initial standard operating procedure (SOP) was created to maximize quality and consistency. Fishermen can buy into the program and use the trademarked logo pending adherence to the SOP. In order for a product to be effective, market demand is needed. An initial survey of high end restaurant owners and chefs found a need for a whole, head-on shell on shrimp product, which can consistently be achieved through plate freezing (Lively, unpublished).

The goal of this research is to develop quantitative and qualitative post-harvest procedure guidelines for LLWPFS, while establishing market demand and preferences. My objectives were to 1) characterize and quantify current plate frozen procedures on board and at docks; 2) determine specific market preferences for the LLWPFS product; 3) establish optimal melanosis prevention practices; and 4) quantify quality standards of plate frozen shrimp. The results of this study will be used to improve the current SOP and recommend best practices for plate freezing shrimp.

\subsection{Methods and Materials}

\subsubsection{Characterizing the Plate Frozen Procedure}

Determining operating procedures of plate freezing boats and docks is essential to ensure consistency in a product. Three overnight trips onboard shrimp fishing vessels and two daytime visits to docks occurred in October and November of 2017. The five trips represented samples of three different businesses using plate freezers. Several 
variables were recorded including tow times, deck temperature, time shrimp remain on the deck, sorting times, post-harvest treatment type for melanosis prevention, grading and rinsing practices, shrimp duration in the chill tank, chill tank water temperature, and total time out of the water until the shrimp were plate frozen. Seawater salinity measurements and water temperatures were recorded (YSI model 30-10FT). Deck and shrimp temperate measurements were recorded using an infrared thermometer (Etekcity Lasergrip 1080, Anaheim, CA). Data was compared to assess the consistency in practice between fishermen. Results were used to help develop a standard operating procedure, under real world conditions, for the LLWPFS program.

\subsubsection{Determine market preference}

In order to determine market preference for the plate frozen product, the New Orleans, Baton Rouge, and Lafayette restaurant markets were surveyed at seafood events. Surveys were distributed to chef's, restaurant owners, and managers that utilize shrimp products in their restaurants. Questions addressed awareness of plate frozen shrimp products, potential order frequency, and packaging preferences. The survey titled "Shrimp Quality Enhancement Through Plate Freezing: New Market Opportunities" was approved for Institutional Review Board (IRB) exemption under IRB\#E11126 (Appendix A and B). In 2018, surveys were distributed and returned back over the course of three seafood-based events. An estimation of plate frozen product needed by restaurants was calculated. Order frequency was standardized to the number of times monthly and yearly, then multiplied by the order size. The options provided for order amount were given by a range; therefore, an upper and lower average was calculated 
by month and year. Unanswered questions were disregarded, and results were analyzed by the number of responses when multiple answers were selected.

\subsubsection{Melanosis Prevention}

\section{Treatment and Vacuum-packaging}

Determining alternative packaging methods to inhibit melanosis was of interest. White shrimp, Litopenaeus setiferus, were purchased directly from a fisherman in November of 2017, in Bayou Dularge, Louisiana. Experimentation occurred on site of the fisherman's seafood processing dock. Approximately $2.04 \mathrm{~kg}$ of shrimp was used in each replicate. Shrimp were placed into clear plastic bags then packaged in individually labeled boxes. Dipped replicates were treated (TR) with a $1 \mathrm{x}$ concentration soak $(2.11$ g/L) of 4-hexyresorcinol product, EverFresh $®$, for two minutes (manufacturer recommended protocol). Control replicates (UT) were not treated or dipped with any additional product. Bags and boxes were identical to those used by plate-freezing fishermen. In vacuum-packaged (VP) replicates, the entire box was vacuum-packed prior to freezing (Ultravac vacuum packing machine by Koch Equipment, LLC, Missouri). All packages were plate frozen on site using the Louisiana Sea Grant Mobile Seafood Quality Training trailer. Once frozen, boxes were returned to the lab and stored in standard consumer grade $-20^{\circ} \mathrm{C}$ freezers. Three frozen storage periods were chosen (T1: one month, T2: 3 months and T3: 6 months), however control shrimp were only evaluated during the first month, as preliminary research indicated untreated shrimp were not acceptable, and the primary interest was testing the effect of packaging method (Table 2.1). There were three replicate boxes of each treatment group. 
Table 2.1. Treatment groups used to test EverFresh ${ }^{\circledR}$ dips and packaging method on black spot inhibition $(n=3)$. Untreated replicates of each packaging method acted as controls.

\begin{tabular}{cccc}
\hline Treatment Name & Dip Type & Box Type & Storage Period \\
\hline UTVP1 & None & Vacuum-pack & 1 Month \\
UTBX1 & None & Standard & 1 Month \\
TRVP1 & EverFresh ${ }^{\circledR}$ & Vacuum-pack & 1 Month \\
TRBX1 & EverFresh & Standard & 1 Month \\
TRVP2 & EverFresh ${ }^{\circledR}$ & Vacuum-pack & 3 Months \\
TRBX2 & EverFresh ${ }^{\circledR}$ & Standard & 3 Months \\
TRVP3 & EverFresh ${ }^{\circledR}$ & Vacuum-pack & 6 Months \\
TRBX3 & EverFresh ${ }^{\circledR}$ & Standard & 6 Months \\
\hline
\end{tabular}

\section{Black Spot Evaluation}

Shrimp were removed from their package at the end of each frozen storage interval and thawed under cool running water. Shrimp were placed on top of ice in individually labeled coolers and stored in an incubator at $4{ }^{\circ} \mathrm{C}$ for ten days. Coolers were removed at approximately the same time on days $1,2,3,4,5,8$, and 10 for black spot evaluation. Five shrimp were randomly selected daily from each cooler and visually scored by two trained evaluators. Only one side of each shrimp was evaluated and remained consistent throughout experimentation. Shrimp were only scored once and discarded after daily evaluation. Coolers were drained and refreshed with ice prior to return to the incubator. Placement inside the incubator was random and varied across the 10 days to minimize error due to internal temperature variation.

\section{Black Spot Scoring}

Scores were determined based on a five-point qualitative scale and independently recorded by each evaluator to prevent bias. This scale was designed for statistical analysis purposes and demonstrates approximately equal progression of 
black spot between each scoring point from 1 to 5 . The scale was set as $1=$ no black spot, $2=$ any black spot beginning on head or body, $3=$ objectionable blackspot resulting in defect points, $4=$ severe black spot on head, body, or both, $5=$ severe black spot on entire exoskeleton, (Figure 2.1). A score of three was set to equal the United States Department of Commerce's Seafood Inspection Manual's definition of objectionable shrimp:

Objectionable black spot refers to more than three instances of penetrating black spot that is visible but difficult to measure because of its small size (approximately the size of a pencil point): or any areas larger than a pencil point that penetrates the flesh: or aggregate areas of non-penetrating surface black spot on the shell or membrane that is equal to or greater than the area of the smallest segment. (USDC 2011).

Shrimp scored greater or equal to 3 were considered unacceptable for markets.

Black Spot Progression Scale

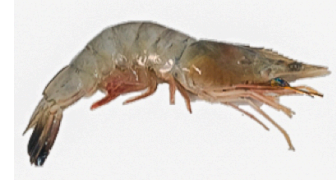

No black spot present

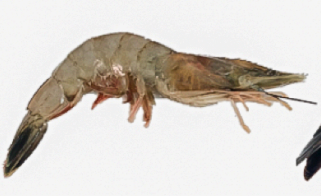

. Objectionable by USDC Seafood Grading Standards

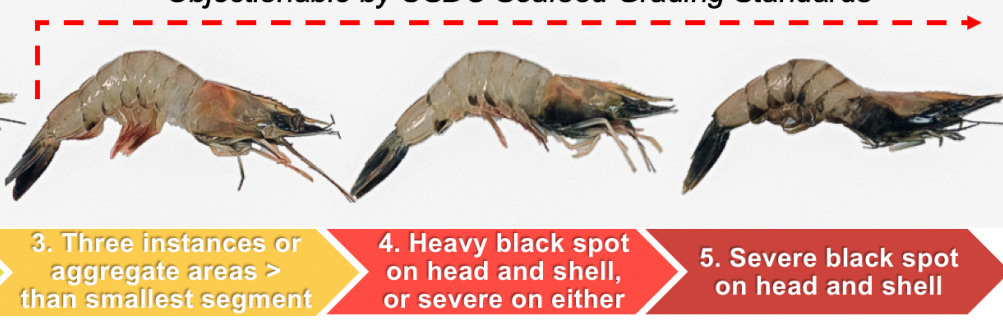

Figure 2.1. Black spot progression scale created for statistical analysis purposes. A score of 3 or higher reflects shrimp considered objectionable by the United States Department of Commerce Seafood Inspection Manual (USDC 2011). All scores are determined by evaluating one side of each shrimp.

Each set of five shrimp was photo documented using a camera (Canon PowerShot SX40 HS) and light box. In situations where only one evaluator was present during scoring, the second score was determined at a later date by evaluating images downloaded to a computer. Scores were averaged for statistical analysis and if scores 
between evaluators differed by more than 1 , a third trained evaluator examined the photo as a tie breaker.

Modified Atmosphere Packaging (MAP)

In order to determine the role of MAP packaging on black spot prevention, fresh white shrimp were purchased from a fisherman in November of 2018 and transported to Lafayette, Louisiana the following day for experimentation. All shrimp were dipped using a $1 \mathrm{x}$ concentration $(2.11 \mathrm{~g} / \mathrm{L})$ soak of EverFresh $®$ for two minutes. Shrimp were packaged in one of four experimental MAP groups (P5-T MAP Unit from PointFive Packaging, LLC, IL), (Table 2.2). MAP packages contained approximately $0.45 \mathrm{~kg}$ of shrimp in each plastic tray and were sealed using one of two atmospheric gas combinations. This weight was the approximate maximum that could fit into the MAP trays used in this system. Shrimp were carefully packaged to prevent shrimp rostrums from piercing the MAP film. The two experimental gas combinations used were MAP100: $100 \% \mathrm{~N}_{2}, 0 \% \mathrm{CO}_{2}$ (Nitrogen UHP 200, Airgas) and MAP50:50: $50 \% \mathrm{~N}_{2}, 50 \%$ $\mathrm{CO}_{2}$ (CT $50 \% \mathrm{NI} / \mathrm{CO} 200$, Airgas). MAP trays were then frozen in a standard $-20^{\circ} \mathrm{C}$ freezer (SF) or plate frozen (PF). PF replicates were frozen in a $-40^{\circ} \mathrm{C}$ contact plate freezer on the LA Sea Grant mobile seafood quality training lab on site. A control group consisted of $2.04 \mathrm{~kg}$ of shrimp packaged in freezer Ziploc bags and frozen via plate freezing. The control contained more shrimp to emulate the smallest boxes typically used by plate frozen entities. SF treatments were returned back to Louisiana State University (LSU) lab and placed in freezers within two hours. All PF samples were frozen overnight and transferred back to $-20^{\circ} \mathrm{C}$ standard freezers at LSU. Packages remained in storage for two freezing intervals, one month (T1) and three months (T2), 
before being evaluated for black spot. Black spot evaluation protocol was identical to the previous experiment (Black Spot Evaluation), except only days 1, 3, 5, 8, and 10 were evaluated. MAP packages only contained approximately $25-30$ shrimp; therefore, only 5 days of analysis was chosen to ensure enough shrimp were available for each daily evaluation.

Table 2.2. Experimental and control treatments used to test MAP on black spot inhibition $(n=3)$. Control shrimp were not packaged using MAP therefore packages contained standard atmospheric gas combinations.

\begin{tabular}{cccc}
\hline Treatment & MAP Gas Combination & Freezing Type & Frozen Time \\
\hline MAP100-PF1 & $100 \% \mathrm{~N}_{2}, 0 \% \mathrm{CO}_{2}$ & Plate & 1 Month \\
MAP100-SF1 & $100 \% \mathrm{~N}_{2}, 0 \% \mathrm{CO}_{2}$ & Standard & 1 Month \\
MAP50:50-PF1 & $50 \% \mathrm{~N}_{2} 50 \% \mathrm{CO}_{2}$ & Plate & 1 Month \\
MAP50:50-SF1 & $50 \% \mathrm{~N}_{2} 50 \% \mathrm{CO}_{2}$ & Standard & 1 Month \\
Control-PF1 & Atmospheric & Plate & 1 Month \\
MAP100-PF2 & $100 \% \mathrm{~N}_{2}, 0 \% \mathrm{CO}_{2}$ & Plate & 3 Months \\
MAP100-SF2 & $100 \% \mathrm{~N}_{2}, 0 \% \mathrm{CO}_{2}$ & Standard & 3 Months \\
MAP50:50-PF2 & $50 \% \mathrm{~N}_{2} 50 \% \mathrm{CO}_{2}$ & Plate & 3 Months \\
MAP50:50-SF2 & $50 \% \mathrm{~N}_{2} 50 \% \mathrm{CO}_{2}$ & Standard & 3 Months \\
Control-PF2 & Atmospheric & Plate & 3 Months \\
\hline
\end{tabular}

Statistics

The effect of treatment on the multinomial response variable, average black spot score, was analyzed using Statistical Analysis Software (SAS Version 9.4). The response variable was not normally distributed, therefore generalized linear mixed models were run using the Proc Glimmix procedure. Models were fit using a cumulative logit function and the independent variable, days post thaw, was treated as a covariate when including frozen storage period in analysis. The covariance structure was established as Autoregressive (order 1). The dependent variable, average black spot 
score, was modeled by the independent treatment groups and months in frozen storage, when necessary. For the vacuum-pack experiment, frozen storage period was not analyzed as it was obvious by inspection that there was no reason to test treatment effect beyond month one. Results are based on the odds ratio of each score being selected. An alpha level of 0.05 was chosen to determine statistical significance.

\subsubsection{Plate Frozen Quality Assessment}

Ten boxes of plate frozen shrimp were purchased between November 2017 and November 2018 from three businesses currently plate freezing shrimp and used for quality analysis. Boxes were stored in chest freezers at $-20^{\circ} \mathrm{C}$ until analysis began in January 2019. Table 2.3 displays initial data of purchased boxes including date, and shrimp and box size.

Table 2.3. Information pertaining to the date and size of plate frozen shrimp packages purchased for analysis. Data represents that reported on the box by each. Identity was kept anonymous by replacing names with A, B and C. Shrimp size reflects the count or number of shrimp per pound. *Shrimp boxes without a labelled size were assumed based on conducted size counts.

\begin{tabular}{cccc}
\hline Box & Date Purchased & Box Size $(\mathrm{kg})$ & Shrimp Size \\
\hline A1 & $5 / 17 / 2018$ & 9.07 & $16 / 20$ \\
A2 & $5 / 17 / 2018$ & 9.07 & $26 / 30$ \\
A3 & $5 / 10 / 2018$ & 4.54 & $21 / 25$ \\
B1 & $9 / 15 / 2018$ & 4.54 & $16 / 20^{*}$ \\
B2 & $9 / 15 / 2018$ & 4.54 & $21 / 25^{*}$ \\
B3 & $8 / 20 / 2018$ & 4.54 & $16 / 20$ \\
C1 & $11 / 3 / 2017$ & 9.07 & $13 / 15$ \\
C2 & $11 / 3 / 2017$ & 9.07 & $13 / 15$ \\
C3 & $11 / 20 / 2018$ & 9.07 & $21 / 25$ \\
C4 & $11 / 20 / 2018$ & 9.07 & $21 / 25$ \\
\hline
\end{tabular}

Shrimp packages contained one or two bags of shrimp placed inside of a box.

The $9.07 \mathrm{~kg}$ boxes contained one large bag, while $4.54 \mathrm{~kg}$ boxes contained two smaller bags of equal size. The total weight of each package was recorded at the start of 
analysis. Shrimp bags were carefully thawed under cool running water and the empty bag and box weight was recorded. Species identification was confirmed. An estimated total frozen shrimp weight was determined by subtracting the bag and box weight from the total package weight. Thawed shrimp were sorted by hand and contaminants, damaged shrimp, inadvertently peeled shrimp (body segments), inadvertently headed and heat-abused shrimp were recorded. Any shrimp damaged during the thawing procedure were not counted. The percentage, by number, of damaged, inadvertently peeled and headed, and heat-abused shrimp was recorded by dividing the total number of each by the estimated total number of shrimp per box. The total number of shrimp was estimated by multiplying the average size count by the number of pounds of shrimp per box. Percentage of contaminants was recorded by dividing total contaminant weight by total shrimp weight. Definitions of each quality standard can be seen in Table 2.4. Following sorting, approximately 40-50 thawed shrimp were pulled at random from each box, placed on ice in a labelled cooler and stored in an incubator at $4^{\circ} \mathrm{C}$ for black spot evaluation (see Section 2.2.3.). At random, $2.5 \mathrm{~kg}$ of shrimp were chosen from each box, stored in $7.57 \mathrm{~L}$ Ziploc bags, and placed in chest freezers for future size count analysis. Of the remaining thawed shrimp, an estimated $0.25 \mathrm{~kg}$ of shrimp was selected at random and homogenized (Continental Electric Food Chopper). In boxes that contained two bags, an approximately equal amount from each bag was chosen for melanosis evaluation, size count analysis and for the homogenized mixture. Samples of the homogenized mixtures were subsequently used for moisture content analysis, salt content analysis and bacterial analysis. All remaining shrimp and homogenized sample were stored in labelled Ziploc bags and returned to freezers. 
Table 2.4. Definition of qualitative measures used to analyze the quality of plate frozen shrimp boxes.

\begin{tabular}{ll}
\hline Quality Standard & Definition \\
\hline Contaminants & $\begin{array}{l}\text { Incidental matter including bycatch, debris, or unusable shrimp. } \\
\text { (size count }>100) \\
\text { Broken pieces of shrimp including pieces of tail, body, or head } \\
\text { damaged in the freezing process }\end{array}$ \\
$\begin{array}{l}\text { Inadvertently } \\
\text { peeled- body }\end{array}$ & $\begin{array}{l}\text { Shrimp with one or more of the abdominal sections removed or } \\
\text { peeled }\end{array}$ \\
$\begin{array}{l}\text { Inadvertently } \\
\text { headed }\end{array}$ & Shrimp with the carapace (head) removed. \\
Heat abuse & Red-orange color shrimp due to over exposure of heat. \\
\hline
\end{tabular}

Moisture Content Analysis

Moisture content was analyzed using basic dehydration techniques in accordance with AOAC (1984) methodology. Approximately $3 \mathrm{~g}$ of each homogenized shrimp sample was weighed and spread across pre-weighed drying dishes. Samples were placed in a drying oven at $100{ }^{\circ} \mathrm{C}$ for approximately 18 hours (adequate time until weight did not change). The final weight of the dish and dried shrimp was recorded. Three replicates for each homogenized sample were analyzed and moisture content was determined by the following equation:

$$
\% \text { Moisture }=\frac{\text { Initial Sample Wt. }- \text { Final Sample Wt. }}{\text { Initial Sample Wt. }} \times 100
$$

Salt Content Analysis

Salt content was determined as a percentage of sodium chloride $(\mathrm{NaCl})$, chlorine as sodium chloride, by a volumetric method in accordance with AOAC Official Methods 937.09 of analysis (AOAC, 1984). Approximately $1 \mathrm{~g}$ of each homogenized sample was weighed and added to a $100 \mathrm{~mL}$ beaker. Exactly $20 \mathrm{~mL}$ of silver nitrite $\left(\mathrm{AgNO}_{3}\right)$ was added followed by $10 \mathrm{~mL}$ of nitric acid $\left(\mathrm{HNO}_{3}\right)$. The sample was boiled under a fume 
hood for 10 minutes, allowed to cool, then filtered through a Whatman No. 1 filter paper into a $200 \mathrm{~mL}$ Erlenmeyer flask using. The filtrate was adjusted to $50 \mathrm{~mL}$ using deionized water, and $5 \mathrm{~mL}$ of ferric aluminum indicator solution was added. The sample was then titrated using potassium thiocyanate $(\mathrm{KSCN})$ until a permanent orange-red color change was achieved. Three replicates from each homogenized sample were analyzed and the following equation was used to determine salt content:

$$
\% \mathrm{NaCl}=5.844 \times\left[\left(\mathrm{V}_{1} \times \mathrm{N}_{1}\right)-\left(\mathrm{V}_{2} \times \mathrm{N}_{2}\right)\right] / \mathrm{W}
$$

Where, $\mathrm{V}_{1}=$ known volume of $\mathrm{AgNO}_{3}(\mathrm{~mL}), \mathrm{N}_{1}=$ Concentration of $\mathrm{AgNO}_{3}(\mathrm{~N}), \mathrm{V}_{2}=$ volume of $\mathrm{KSCN}$ used $(\mathrm{mL}), \mathrm{N}_{2}=$ Concentration of $\mathrm{KSCN}(\mathrm{N})$, and $\mathrm{W}=$ sample weight (g).

\section{Bacterial Analysis}

Approximately $100 \mathrm{~g}$ of homogenized samples was stored in Falcon tubes and frozen. Frozen samples were delivered to the Food and Microbial Testing Lab at LSU for Aerobic Plate Count (APC) and total coliform analysis. AOAC official methods were used to determine bacterial counts and samples were analyzed in triplicate.

\section{Size Count Analysis}

Approximately two weeks after initial analysis of boxes, the $2.5 \mathrm{~kg}$ labelled bags were removed and thawed under cool water. Shrimp from each replicate were spread across a tray, chosen at random, and placed on a scale until a weight of one pound was reached. The number of shrimp contained in each pound was then recorded. An actual average shrimp size was calculated within each box by taking the average of five replicates of pound counts. This was then compared to the expected size count, which was determined as the middle size of the labelled range. Percent deviance from both 
the expected average and expected minimum size was determined by dividing actual sizes by expected.

Sulfite Residue

Ten shrimp were chosen at random and tested for residual sulfite using an Alert® for Sulfites in Seafood (Neogen Food Safety, Lansing, MI) dye test. Sulfite content was determined by a color change of the blue dye and is represented by a range of concentrations. No color change indicates $<10$ ppm residual sulfite, pink/violet indicates between 10-100 ppm, and clear indicates greater than 100 ppm. Shrimp were peeled and one drop of activator solution was added to the second largest segment of flesh, followed by one drop of dye reagent in the same location. Samples were allowed one minute to change color before the final color was visually analyzed against a provided range to determine an estimate of residual sulfite in parts per million.

\subsection{Results}

\subsubsection{Characterizing the Plate Frozen Procedure}

The first trip aboard a skimmer boat occurred within marsh waters and bayous west of Cut Off, Louisiana. A total of three tows were recorded with an average tow time of $92 \pm 10$ minutes. The salinity of the saltbox was recorded at 58.4 ppt during the first tow, however salt was not added for latter tows. The time required to sort bycatch from shrimp averaged $81 \pm 15$ minutes, however only two records were achieved as the third tow yielded minimal shrimp. Shrimp were placed in a chill tank with a temperature of approximately $35-40^{\circ} \mathrm{C}$ after an average of $105 \pm 21$ minutes from being landed. Approximately $136 \mathrm{~kg}$ of shrimp were caught during the first two successful tows. All 
shrimp were below marketable size for consumption, therefore no grading occurred, and shrimp were plate frozen the following day to be sold for bait (Table 2.5).

Two multi-day trips were taken aboard an otter trawl vessel fishing within state waters in October and November of 2017. Data from these two trips was pooled together for some variables, as they occurred on the same ship with the same crew. The average tow time was $212 \pm 40$ minutes $(n=7)$. Sorting times varied greatly ranging from 35-110 minutes with an average of $69 \pm 27$ minutes. The salinity of the saltbox used to assist in sorting averaged $64.9 \pm 10 \mathrm{ppt}(\mathrm{n}=4)$. The chill tank was only used in the first trip, and it took an average of $67 \pm 28$ minutes to place catch in the chill tank after hauling on the deck $(n=3)$. Shrimp from the second trip were bagged, boxed and frozen directly after sorting and rinsing. Across both trips it took an average of $167 \pm$ 147 minutes for catch to be boxed and placed in the $-40{ }^{\circ} \mathrm{C}$ plate freezer. Only half of the shrimp from the first trip were plate frozen, while the rest were placed in an ice hold and treated with sodium bisulfite. None of the shrimp from the second trip were treated with any additive for melanosis inhibition. The first trip yielded approximately $195 \mathrm{~kg}$ of shrimp across three tows, while the second trip yielded approximately $610 \mathrm{~kg}$ over four tows. The average catch weight per tow was $114 \mathrm{~kg}(\mathrm{n}=7)$. Rinsing and grading occurred on both trips (Table 2.5). Some of the variability in post-harvest procedures is a result of small shrimp being caught that typically aren't treated or plate frozen. 
Table 2.5. Data collected onboard three plate freezing commercial shrimp vessels in October and November of 2017. Grading occurred by hand and treatment occurred using sodium bisulfites. * Only half of the caught shrimp were plate frozen. ${ }^{* *}$ All time measurements were recorded in minutes.

\begin{tabular}{|c|c|c|c|c|c|c|c|c|c|c|}
\hline \multirow{2}{*}{$\begin{array}{l}\text { Boat Type } \\
\text { Tow \# }\end{array}$} & \multicolumn{3}{|c|}{$\begin{array}{c}\text { Skimmer } \\
(10 / 11 / 17)\end{array}$} & \multicolumn{3}{|c|}{$\begin{array}{c}\text { Otter Trawl } \\
(10 / 14 / 17-10 / 15 / 17)\end{array}$} & \multicolumn{4}{|c|}{$\begin{array}{c}\text { Otter Trawl } \\
(11 / 7 / 17-11 / 09 / 17)\end{array}$} \\
\hline & 1 & 2 & 3 & 1 & 2 & 3 & 1 & 2 & 3 & 4 \\
\hline $\begin{array}{l}\text { Tow } \\
\text { duration** }\end{array}$ & 100 & 95 & 80 & 191 & 254 & 199 & 180 & 195 & 285 & 185 \\
\hline $\begin{array}{l}\text { Saltbox } \\
\text { salinity (ppt) }\end{array}$ & 58.4 & $\mathrm{n} / \mathrm{a}$ & $\mathrm{n} / \mathrm{a}$ & 73 & 71.8 & 66.9 & 47.9 & $\mathrm{n} / \mathrm{a}$ & $\mathrm{n} / \mathrm{a}$ & $\mathrm{n} / \mathrm{a}$ \\
\hline Time to sort** & 92 & 70 & $\mathrm{n} / \mathrm{a}$ & 35 & 93 & 52 & 75 & 75 & 110 & 45 \\
\hline Grading & No & No & No & Yes & Yes & Yes & No & Yes & Yes & Yes \\
\hline Time to chill** & 120 & 90 & $\mathrm{n} / \mathrm{a}$ & 46 & 100 & 57 & $\mathrm{n} / \mathrm{a}$ & $\mathrm{n} / \mathrm{a}$ & $\mathrm{n} / \mathrm{a}$ & $\mathrm{n} / \mathrm{a}$ \\
\hline Treated & No & No & No & Yes & Yes & No & No & No & No & No \\
\hline Time to $P F^{* *}$ & $\mathrm{n} / \mathrm{a}$ & $\mathrm{n} / \mathrm{a}$ & $\mathrm{n} / \mathrm{a}$ & 493 & 138 & 76 & 110 & 100 & 165 & 90 \\
\hline Shrimp (kg) & 54 & 82 & $<25$ & $45^{*}$ & $113^{*}$ & 36 & 181 & $113^{*}$ & 245 & 68 \\
\hline
\end{tabular}

Two different dockside plate freezing units were visited in October and November of 2017. For the first trip, catch was held in a chill tank from the previous night's fishing trip. It was estimated that catch was in a $35-40^{\circ} \mathrm{C}$ chill tank for approximately 12 hours or less. Once removed, it took approximately 25 minutes to bag, box, and place $181 \mathrm{~kg}$ of shrimp into the plate freezer.

The second plate freezing unit was located at a processing plant in Terrebonne Parish, Louisiana. A large chill tank holding approximately $254 \mathrm{~kg}$ of shrimp was hauled off of a closed trailer into the facility. It was estimated that shrimp were held in the 46.5 ${ }^{\circ} \mathrm{C}$ chill tank for less than 24 hours. The chill tank temperature was not mechanically controlled and consisted of ice and water, therefore was most likely at its warmest temperature when recorded. It took approximately 45 minutes to bag, box and place 
$254 \mathrm{~kg}$ of shrimp onto plate freezing racks inside the frozen storage room. The storage room was held at approximately $-20^{\circ} \mathrm{C}$, however the contact racks were $-40^{\circ} \mathrm{C}$.

Table 2.6. Data collected at two businesses utilizing dockside plate freezing units.

\begin{tabular}{lcc}
\hline \multicolumn{3}{c}{ Dockside Plate Freezing } \\
\hline Owner & "B" Dock & "C" Dock \\
Date & $10 / 11 / 17$ & $11 / 3 / 17$ \\
Time in Chill Tank $(\mathrm{hrs})$ & $<12$ & $<24$ \\
Chill Tank Temp $\left({ }^{\circ} \mathrm{C}\right)$ & 36 & 46.5 \\
Chill tank to PF $($ min.) & 25 & 46 \\
Deck Temp $\left({ }^{\circ} \mathrm{C}\right)$ & 87 & $\mathrm{n} / \mathrm{a}$ \\
Shrimp Temp $\left({ }^{\circ} \mathrm{C}\right)$ & $\mathrm{n} / \mathrm{a}$ & 52 \\
Shrimp $(\mathrm{kg})$ & 181 & 254 \\
\hline
\end{tabular}

\subsubsection{Determine Market Preference}

A total of 29 surveys were distributed to chefs, restaurant owners, and managers at three events in Louisiana: Louisiana Seafood Cookoff (LASCO) combined with A Taste of Eat Lafayette $(n=7)$, Southern Food and Beverage Best of Bycatch: Asian Carp Cookoff $(n=3)$, and Louisiana Restaurant Association 2018 Expo $(n=19)$. Questions can be broken up into two broad categories: Awareness and Use, and Delivery and Package Preference.

Awareness and Use

The first five questions from the survey were answered by all respondents. When asked "Are you aware of premium plate frozen shrimp?", 65.5\% $(n=19)$ responded "No" while, 34.5\% $(n=10)$ responded "Yes". Of the 10 respondents that were aware of the technology and product, only $30 \%(n=3)$ had used premium plate frozen shrimp in the past and currently do as well. When asked if they were aware of LLWPFS specifically, 8 responded yes and 21 responded no. Of those aware of plate frozen shrimp in general, $80 \%$, knew of the LLWPFS brand. Eighty-six percent $(n=25)$ of respondents stated that 
they had a use for a product of this nature in their restaurant. When asked whether the respondent was interested in learning more about LLWPFS, 88.5\% $(n=23)$ were interested in learning more. Options were provided for each respondent's preferred method of receiving more information on the product and additional information was provided when requested.

\section{Delivery and Package Preference}

The following questions were asked to better understand the preferred size and frequency of orders. When asked how much PFS product would be ordered at one time. The most common response was "50 -100 pounds" with $44.4 \%$ of replies $(n=12)$, followed by "100 - 300 " $25.9 \%(n=7)$ of the time, and "less than 50 pounds" $18.5 \%$ of the time $(n=5)$. The least common response was "greater than 300 pounds", selected by only $11.1 \%(n=3)$ of those surveyed. When asked how often the product would be ordered, the most frequent response was "weekly" $65.4 \%(n=17)$. All other responses were selected with similar frequency: " $3-4$ days" $15.4 \%$ of the time $(n=4)$, followed by "Twice Monthly" $11.5 \%(n=3)$ and finally "Monthly" $7.6 \%(n=2)$. Estimations calculated from order frequency and size responses indicated that shrimpers can expect restaurants to order approximately $362-585$ pounds per month, or $4,325-7,025$ pounds per year (Table 2.7).

Size preferences for shrimp were determined by giving four size classes and an "other" option for free response. The size counts reflect approximately how many shrimp constitute one pound. Some respondents selected more than one size class so percentages reflect answers out of the total number of selections $(n=34)$. The most preferred size class was $16 / 20$ 's $35.3 \%$ of the time $(n=12)$. The second most occurring 
response was $26 / 30$ 's at $20.6 \%(n=7)$ followed by $10 / 15$ 's at $17.6 \%(n=6)$ of the time. Four respondents selected "other" and the most frequently occurring responses were shrimp larger than the options given. For example, "U6" was a response indicating chefs wanted large shrimp that were under 6 shrimp per pound. The last question pertaining to preference determined the ideal size box or package. Five packaging options were given with box size, and the number of bags within each box. The "other" option was also given with a free response line. More than one option was selected by several respondents, and therefore all percentages are out of the total number of selections $(n=32)$. The most common preferred package was $5 \mathrm{lb}$. boxes with one bag selected $40.6 \%(n=13)$ of the time. The second and third most selected replies involved two bags within the same box: 20lb. boxes with 2 bags was the second most occurring response at $18.8 \%(n=6)$ followed by $10 \mathrm{lb}$. boxes with 2 bags at $12.5 \%(n=4)$ of the time. The "other" option was selected 5 times and responses included $1 \mathrm{lb} ., 25 \mathrm{lb}$., and three responses of $50 \mathrm{lb}$. packages.

Table 2.7. Monthly and annual estimation of order frequencies of plate frozen shrimp. Values represent an average of responses based on 26 surveys from seafood chefs and restaurant owners.

\begin{tabular}{ccccccc}
\hline $\begin{array}{c}\text { Min. } \\
\text { Order } \\
\text { Amount }\end{array}$ & $\begin{array}{c}\text { Max. } \\
\text { Order } \\
\text { Amount }\end{array}$ & $\begin{array}{c}\text { Freq. } \\
\text { per } \\
\text { Month }\end{array}$ & $\begin{array}{c}\text { Monthly } \\
\text { Min. }\end{array}$ & $\begin{array}{c}\text { Monthly } \\
\text { Max. }\end{array}$ & $\begin{array}{c}\text { Yearly } \\
\text { Min. }\end{array}$ & $\begin{array}{c}\text { Yearly } \\
\text { Max. }\end{array}$ \\
\hline 90 & 148 & 4 & 362 & 585 & 4343 & 7025 \\
\hline
\end{tabular}

\subsubsection{Melanosis Prevention}

Treatment and Vacuum-packaging

The goal of the first black spot evaluation experiment was to determine the effect of a 4-HR dip, plate freezing, and vacuum-packaging on melanosis in shrimp. The 
average melanosis scores of treatment groups were significantly different from each other after one month of frozen storage $(F=60.90, P<0.0001)$. Replicates that were dipped with EverFresh $\AA(T R)$ remained below the unacceptable level $(<3)$ for all 10 days, regardless of freezer length or packaging type (Figure 2.2). Control (UT) groups became unacceptable $(\geq 3)$ by day 3 for both vacuum-packaging and standard treatments (Figure 2.2).

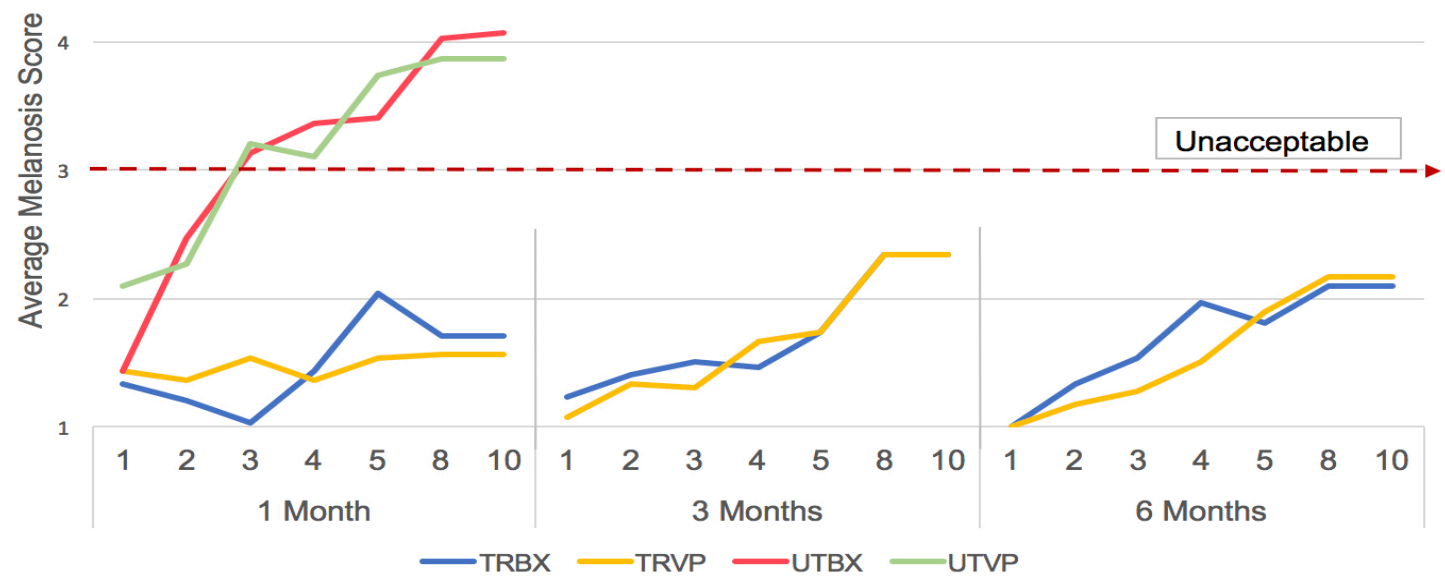

Figure 2.2. Average melanosis scores per day of plate frozen shrimp groups over three frozen storage intervals. Shrimp were dipped with Everfresh ${ }^{\circledR}(T R)$ or untreated (UT) and either vacuum-packaged (VP) or frozen in standard boxes (BX).

The average score of all days combined was approximately 1.5 for dipped replicates, while controls averaged slightly over 3 (Figure 2.3). The frozen storage interval was removed from statistical analysis, as it was obvious by inspection that further analysis was not required. None of the daily average scores ever reached unacceptable levels in any of the dipped experiment groups, regardless of frozen storage time (Table 2.8). 


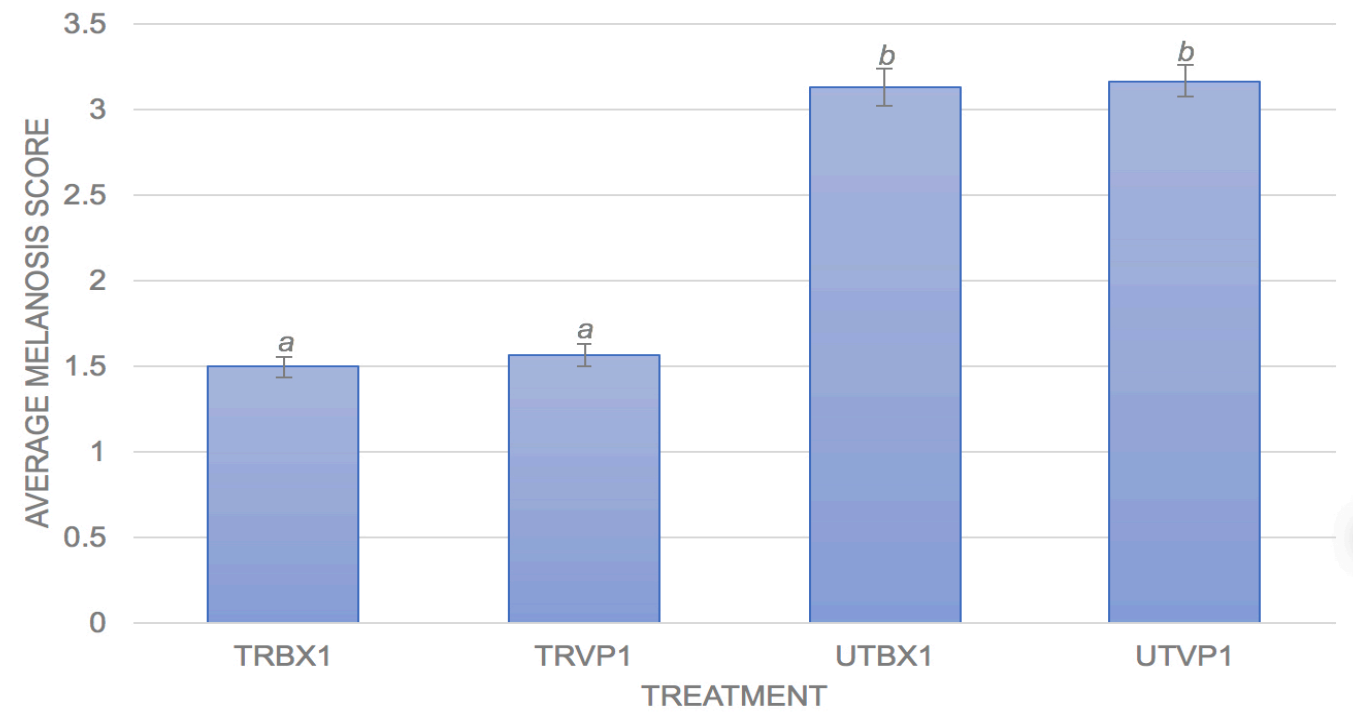

Figure 2.3. Average melanosis scores over 10 days for experimental and control groups of plate frozen shrimp. Shrimp were dipped with Everfresh ${ }^{\circledR}(T R)$ or untreated (UT) and either vacuum-packaged (VP) or frozen in standard boxes (BX). Groups were significantly different based on generalized linear mixed models $(F=60.90, P<0.0001)$, and different letters indicate statistical differences. Error bars represent the standard error within each treatment.

Table 2.8. Average daily scores of experimental and control groups. Each score represents an average of three replicates with five shrimp scored in each replicate.

\begin{tabular}{ccccccccc}
\hline Day & UTVP1 & UTBX1 & TRVP1 & TRBX1 & TRVP2 & TRBX2 & TRVP3 & TRBX3 \\
\hline 1 & 2.1 & 1.4 & 1.4 & 1.3 & 1.1 & 1.2 & 1.0 & 1.0 \\
2 & 2.3 & 2.5 & 1.4 & 1.2 & 1.3 & 1.4 & 1.2 & 1.3 \\
3 & 3.2 & 3.1 & 1.5 & 1.0 & 1.3 & 1.5 & 1.3 & 1.5 \\
4 & 3.1 & 3.4 & 1.4 & 1.4 & 1.7 & 1.5 & 1.5 & 2.0 \\
5 & 3.7 & 3.4 & 1.5 & 2.0 & 1.7 & 1.7 & 1.9 & 1.8 \\
8 & 3.9 & 4.0 & 2.1 & 1.7 & 1.8 & 2.1 & 2.4 & 2.0 \\
10 & 3.9 & 4.1 & 1.6 & 1.7 & 2.3 & 2.3 & 2.2 & 2.1 \\
\hline Avg. & 3.2 & 3.1 & 1.6 & 1.5 & 1.6 & 1.7 & 1.6 & 1.7 \\
\hline
\end{tabular}

Modified Atmosphere Packaging (MAP)

In order to determine the effect of MAP on melanosis inhibition of plate frozen shrimp, the average melanosis score for treatments was analyzed with effect of storage period. Days of analysis post thaw was an appropriate covariable with an estimate of 
0.1428 and standard error of 0.2029. All shrimp were 4-HR dipped, and on average, none reached unacceptable $(\geq 3)$ scores within ten days of thawing in either frozen storage interval (Figure 2.4). There was no statistical significance of treatment effect $(F=0.64, P=0.6372)$ or the interaction between treatment and frozen storage interval $(F=1.74, P=0.1376)$ based on generalized linear mixed models. The likelihood of detecting an average melanosis score was significantly different between month one and three $(F=36.29, P<0.0001)$.

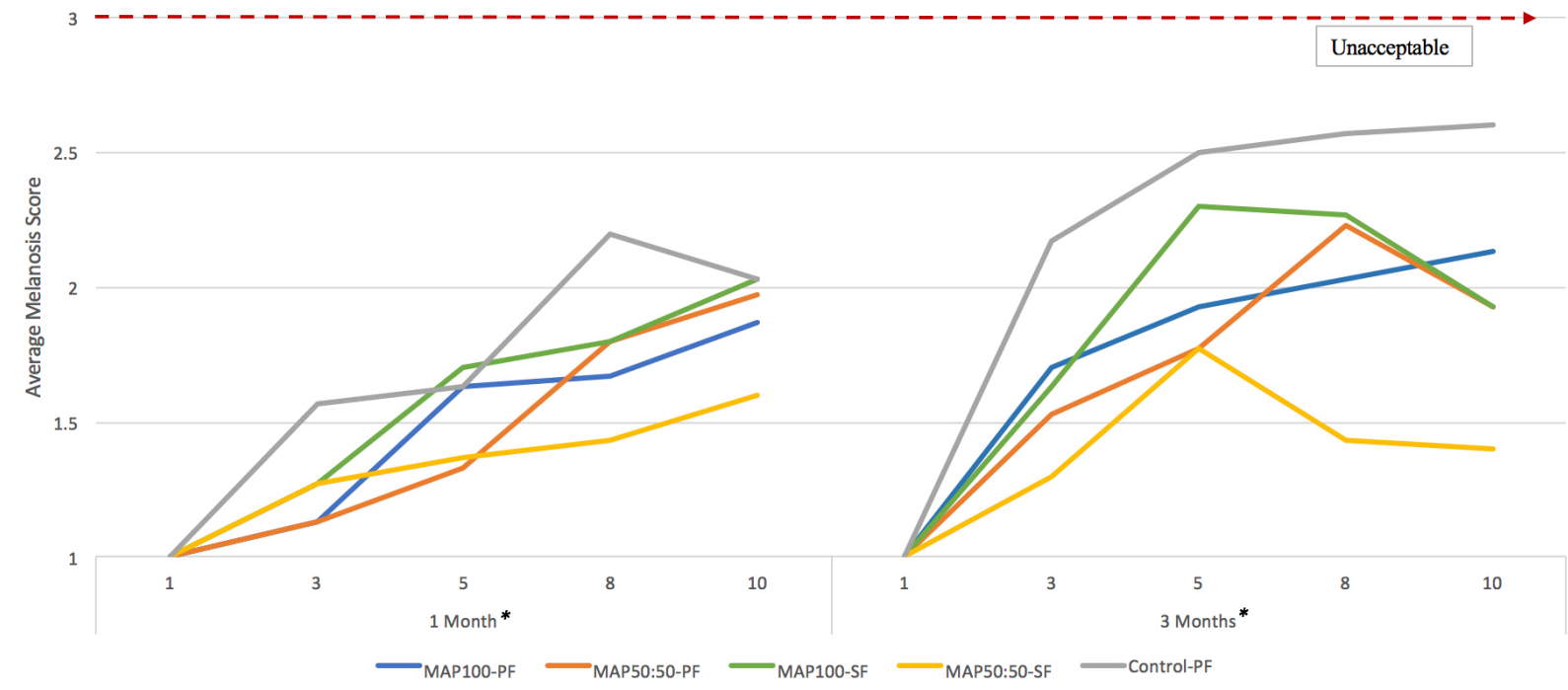

Figure 2.4. Average melanosis scores per day of treatments of modified atmosphere packaged (MAP) shrimp over the course of two freezing intervals. Scores greater than 3 are considered objectionable by USDC standards. Months 1 and 3 were significantly different $(\mathrm{F}=36.29, \mathrm{P}<0.0001)$. MAP100 $=$ (Modified Atmosphere Pack, 100\% $\mathrm{N}_{2} 0 \%$ $\mathrm{CO}_{2}$ ), MAP50:50= (Modified Atmosphere Pack, $50 \% \mathrm{~N}_{2} 50 \% \mathrm{CO}_{2}$, Plate Frozen), SF= (Standard Frozen), $\mathrm{PF}=$ (Plate Frozen). Error bars represent the standard error within each treatment group.

After one month of frozen storage MAP50:50-SF had the lowest average score of 1.3, while the control group had the highest score of 1.7. After three months, the average melanosis score of each treatment increased. MAP100-SF, once again, had 
the lowest average score at 1.4 and the control had the highest at 2.2. The three remaining variables ranged from 1.7-1.8 (Figure 2.5).

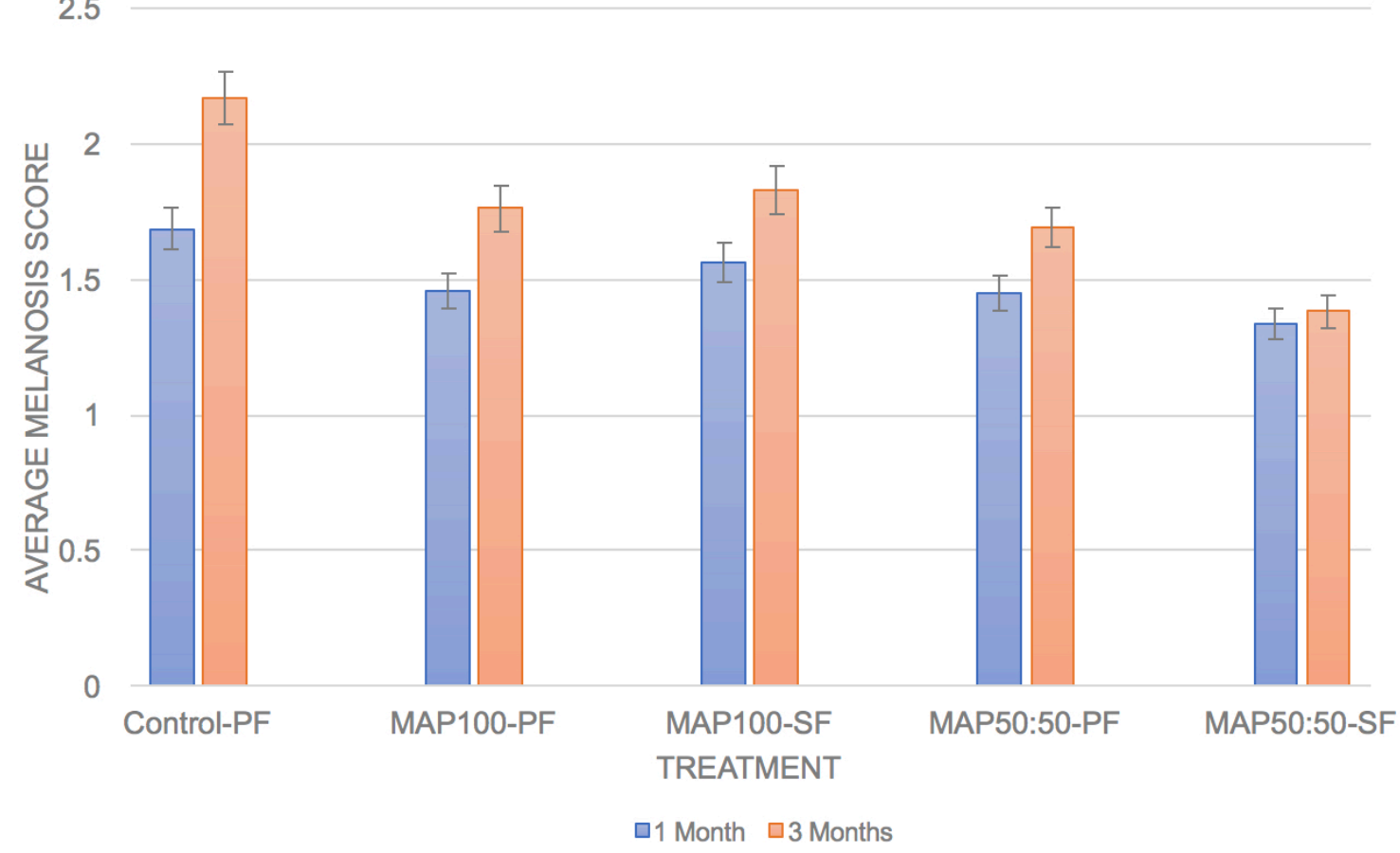

Figure 2.5. Melanosis scores per frozen storage period for treatments of modified atmosphere packaged (MAP). Treatment groups were not significantly different based on generalized linear mixed models $(F=0.64, P=0.6372)$. MAP100 $=$ (Modified Atmosphere Pack, $100 \% \mathrm{~N}_{2}$ 0\% $\mathrm{CO}_{2}$ ), MAP50:50= (Modified Atmosphere Pack, 50\% $\mathrm{N}_{2}$ $50 \% \mathrm{CO}_{2}$, Plate Frozen), SF= (Standard Frozen), PF= (Plate Frozen) Error bars represent the standard error within each treatment group.

\subsubsection{Plate Frozen Quality Evaluation}

In order to quantify LLWPFS quality, product available for purchase was obtained from the three partners and evaluated. Total shrimp weight from all ten boxes was higher than the labelled package we9ight. The overall physical condition of plate frozen shrimp remained intact throughout the packaging and freezing process. The majority of 
boxes had less than $1 \%$ by number damaged and inadvertently peeled shrimp. Boxes C1 and C2 contained the most damaged shrimp at 3.2 and 2.1\%, and the most inadvertently peeled between 2 and 3\% (Table 2.9). Contaminants were low in all packages ranging from 0 to $26 \mathrm{~g}$ with no package exceeding $1 \%$ contaminants by weight. Residual sulfite analysis revealed no color changes indicating no samples exceeded $10 \mathrm{ppm}$ residue concentrations (Table 2.9). There was no evidence of heat abuse in any shrimp, therefore the variable was eliminated.

Table 2.9. Qualitative analysis of plate frozen shrimp quality. Contaminants were recorded as percentage of the box by weight. Damaged and inadvertently peeled shrimp represent percentage of the box by number.

\begin{tabular}{cccccc}
\hline Source & $\begin{array}{c}\text { Damaged } \\
\text { Shrimp (\%) }\end{array}$ & $\begin{array}{c}\text { Inadvertently } \\
\text { Peeled (Body) } \\
(\%)\end{array}$ & $\begin{array}{c}\text { Inadvertently } \\
\text { Peeled (Head) } \\
(\%)\end{array}$ & $\begin{array}{c}\text { Contaminants } \\
(\%)\end{array}$ & $\begin{array}{c}\text { Residual } \\
\text { Sulfite } \\
(\mathrm{ppm})\end{array}$ \\
\hline A1 & $<1.0$ & 0.0 & $<1.0$ & $<1.0$ & $<10$ \\
A2 & $<1.0$ & 0.0 & $<1.0$ & $<1.0$ & $<10$ \\
A3 & $<1.0$ & 0.0 & $<1.0$ & $<1.0$ & $<10$ \\
B1 & $<1.0$ & 0.0 & $<1.0$ & $<0.1$ & $<10$ \\
B2 & $<1.0$ & 0.0 & $<1.0$ & 0.0 & $<10$ \\
B3 & $<1.0$ & 0.0 & $<1.0$ & 0.0 & $<10$ \\
C1 & 3.2 & $<1.0$ & 2.3 & $<0.1$ & $<10$ \\
C2 & 2.1 & 0.0 & 2.7 & $<0.1$ & $<10$ \\
C3 & $<1.0$ & 0.0 & $<1.0$ & $<1.0$ & $<10$ \\
C4 & $<1.0$ & 0.0 & $<1.0$ & $<0.1$ & $<10$ \\
\hline
\end{tabular}

Moisture and Salt Content Analysis

Based on a total of thirty replicates $(n=30)$, three from each of ten boxes, salt content ranged from $1.64-2.39 \%$ with an average of $2.05 \pm 0.29 \%$. Moisture content ranged from $75.6-80.7 \%$ with an average of $77.97 \pm 1.77 \%$. Shrimp from source A had the lowest average moisture content $(76.7 \%)$ and the highest average salt content (2.3\%). Shrimp from source $C$ had the lowest average salt content of 1.83 (Table 2.10). 
Table 2.10. Moisture and salt content of plate frozen shrimp packages purchased from three sources. All values are an average of three replicates.

\begin{tabular}{cccc}
\hline Source & Box \# & Percent Moisture & Salt Content $(\% \mathrm{NaCl})$ \\
\hline A & 1 & 77.68 & 2.39 \\
A & 2 & 75.69 & 2.25 \\
A & 3 & 76.68 & 2.38 \\
B & 1 & 78.94 & 1.88 \\
B & 2 & 80.71 & 1.88 \\
B & 3 & 77.96 & 2.39 \\
C & 1 & 80.48 & 1.64 \\
C & 2 & 79.21 & 1.89 \\
C & 3 & 75.88 & 1.83 \\
C & 4 & 76.48 & 1.96 \\
\hline
\end{tabular}

Size Counts Analysis

Size counts of shrimp were analyzed against the range labelled on each box to determine accuracy in sizing. The actual average size count, determined by five randomly selected pound counts, of seven of the ten packages was smaller than the expected average. This indicated more shrimp fell on the smaller size of the range, but not necessarily outside the declared range. However, four of the ten packages fell completely below the expected minimum size, including one box from each source (Table 2.11). Packages are allowed five percent leeway before being in violation for undersized shrimp based on the current standards for Louisiana Limited shrimp. Boxes C1 and C2 are the only samples that are in violation at 21 and $20 \%$ under the expected minimum size, respectively. Box A1 was the only package with an actual average shrimp size that was larger and completely outside the labelled range. 
Table 2.11. Expected and actual size range of plate frozen shrimp boxes purchased from three sources. Five pound counts were weighed from each box to get an average for actual size \pm standard deviation. Positive percent differences represent shrimp larger than labelled ranges, while negatives are smaller than expected. *Shrimp boxes without a labelled size were assumed based on the size counts.

\begin{tabular}{ccccccc}
\hline Source & $\begin{array}{c}\text { Size } \\
\text { Range }\end{array}$ & $\begin{array}{c}\text { Expected } \\
\text { Average } \\
\text { Size }\end{array}$ & $\begin{array}{c}\text { Expected } \\
\text { Minimum } \\
\text { Size }\end{array}$ & $\begin{array}{c}\text { Actual } \\
\text { Average } \\
\text { Size }\end{array}$ & $\begin{array}{c}\text { Difference } \\
\text { from Exp. } \\
\text { Avg. (\%) }\end{array}$ & $\begin{array}{c}\text { Difference } \\
\text { from Exp. } \\
\text { Min. (\%) }\end{array}$ \\
\hline A1 & $16 / 20$ & 18 & 20 & $15.6 \pm 0.54$ & 13.33 & 22.00 \\
A2 & $26 / 30$ & 28 & 30 & $30.4 \pm 1.67$ & -8.57 & -1.33 \\
A3 & $21 / 25$ & 23 & 25 & $24.8 \pm 1.30$ & -7.83 & 0.80 \\
B1 & $16 / 20^{*}$ & 18 & 20 & $19.6 \pm 0.89$ & -8.89 & 2.00 \\
B2 & $21 / 25^{*}$ & 23 & 25 & $23.4 \pm 1.14$ & -1.74 & 6.40 \\
B3 & $16 / 20$ & 18 & 20 & $20.2 \pm 0.45$ & -12.22 & -1.00 \\
C1 & $13 / 15$ & 14 & 15 & $18.2 \pm 0.84$ & -30.00 & -21.33 \\
C2 & $13 / 15$ & 14 & 15 & $18.0 \pm 1.41$ & -28.57 & -20.00 \\
C3 & $21 / 25$ & 23 & 25 & $21.0 \pm 0.71$ & 8.70 & 16.00 \\
C4 & $21 / 25$ & 23 & 25 & $21.4 \pm 0.55$ & 6.96 & 14.40 \\
\hline
\end{tabular}

\section{Bacterial Analysis}

Aerobic plate count (APC) and total coliforms was determined by samples from each box to ensure shrimp were within acceptable levels. APC values ranged from $1.5 \mathrm{x}$ $10^{3}$ to $1.4 \times 10^{5}$ with an average of $3.0 \times 10^{4} \pm 4.3 \times 10^{4}$ colony forming units per gram (CFU/g). Shrimp boxes from source A had both the highest and lowest APC values. Samples from source B and C had similar APC ranges around $2.2 \times 10^{4}$ and $1.8 \times 10^{4}$ CFU/g, respectively. The International Commission on Microbiological Specification for Foods sets the upper limit of APC at $10^{6} \mathrm{CFU} / \mathrm{g}$ for good quality shrimp and all samples were under this limit (ICMSF 1986). Total coliform values ranged from $<10$ to 845 and averaged less than $250 \mathrm{CFU} / \mathrm{g}$. Samples from box A were again the most variable, 
while box $\mathrm{B}$ was the most consistent at $<250 \mathrm{CFU} / \mathrm{g}$ for each sample. All samples were negative for generic Escherichia coli (Table 2.12).

Table 2.12. Bacterial analysis of plate frozen shrimp boxes from three sources. All sample results were within the federally accepted range considered as good quality for shrimp products.

\begin{tabular}{cccc}
\hline Source & Log $_{10}$ APC $(\mathrm{CFU} / \mathrm{g})$ & Coliforms $(\mathrm{CFU} / \mathrm{g})$ & E. coli \\
\hline A1 & 3.18 & $<10$ & Negative \\
A2 & 4.70 & $<250$ & Negative \\
A3 & 5.16 & 845 & Negative \\
B1 & 4.53 & $<250$ & Negative \\
B2 & 4.06 & $<250$ & Negative \\
B3 & 4.26 & $<250$ & Negative \\
C1 & 4.08 & $<250$ & Negative \\
C2 & 3.62 & $<10$ & Negative \\
C3 & 4.35 & $<250$ & Negative \\
C4 & 3.35 & $<10$ & Negative \\
\hline
\end{tabular}

Melanosis analysis

Plate frozen shrimp were analyzed for melanosis to determine if proper treatment procedures were being used onboard. Application and treatment method of black spot prevention was unknown for each box. Black spot scores of a 3 or greater were considered objectionable or unacceptable. Half of the samples developed objectionable black spot within four days ( $A 1, A 2, A 3, C 3$ and $C 4)$, while the others remained within acceptable levels for all ten days of analysis (B1, B2, B3, C1 and C2). Shrimp from all the A boxes reached unacceptable levels, while shrimp from all B boxes were acceptable (<3) (Figure 2.6). Box A2 had the highest average black spot score of 4.11 and became objectionable the quickest, within two days of thawing. Boxes B1 and C2 had the lowest average black spot score at 1.6 (Table 2.13). 
Table 2.13. Daily melanosis scores of shrimp from ten plate frozen shrimp boxes. Similar letters represent shrimp from the same source or business. Each score represents an average of three replicates with five shrimp scored in each replicate.

\begin{tabular}{ccccccccccc}
\hline Day & A1 & A2 & A3 & B1 & B2 & B3 & C1 & C2 & C3 & C4 \\
\hline 1 & 1.8 & 2 & 1.4 & 1 & 1.1 & 1 & 1 & 1 & 1 & 1.2 \\
2 & 2.6 & 3.8 & 2.5 & 1.5 & 2.1 & 1.6 & 1.4 & 1 & 2.4 & 2.4 \\
3 & 3.4 & 4.7 & 2.7 & 2.1 & 1.7 & 1.8 & 1.8 & 1.9 & 3.1 & 3.1 \\
4 & 3.9 & 4.2 & 3.8 & 1.6 & 2 & 2.2 & 1.8 & 1.7 & 3.4 & 3.2 \\
5 & 4 & 4.4 & 4.1 & 1.3 & 2.1 & 1.7 & 1.8 & 1.8 & 3.9 & 3.9 \\
8 & 4.6 & 4.7 & 3.5 & 2 & 2.1 & 1.5 & 1.9 & 1.9 & 4.3 & 4 \\
10 & 4.6 & 5 & 4.2 & 1.7 & 2.1 & 1.8 & 2.1 & 2.2 & 4.2 & 4.4 \\
\hline Avg. & 3.6 & 4.1 & 3.2 & 1.6 & 1.9 & 1.7 & 1.7 & 1.6 & 3.2 & 3.2 \\
\hline
\end{tabular}

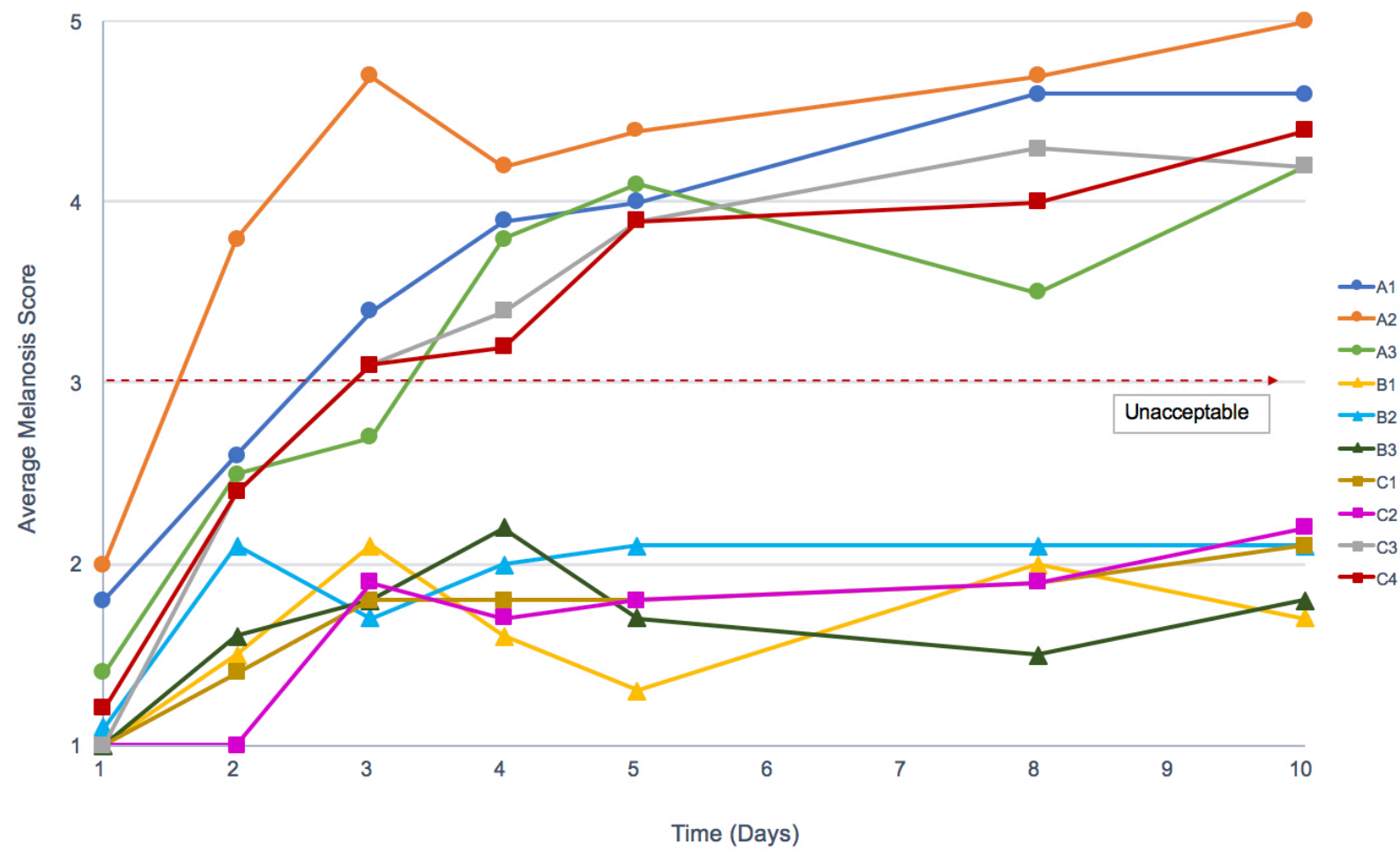

Figure 2.6. Melanosis scores of treatments of plate frozen shrimp purchased from three different sources over ten days post-thaw. Scores greater than 3 are considered objectionably by grading standards (USDC 2011). Each line represents a sample and similar letters and marker shape represent samples from the same source. 


\subsection{Discussion}

The importance of the commercial shrimp industry to Louisiana has been unparalleled in the past century. Many locals grew up fishing and have solely relied on the resource for their income and well-being. Pressure from foreign imports has contributed to the massive decline of shrimpers and will continue to do so if changes are not made. Despite shifting tariff structure and anti-dumping laws, relief has been minimal LLWPFS hopes to provide economic opportunity to help sustain the livelihoods of fishermen, but is only possible with quantifiable standards and a realistic standard operating procedure for fishermen to follow. Despite the variability observed in postharvest procedures, improved consistency in handling and proper treatment with 4-HR could create a premium, plate frozen shrimp product that meets the demand of the highend seafood market.

While available ride along trips did not always catch large, high quality shrimp for plate freezing, trips aboard plate freezing vessels revealed inconsistencies in the operating procedures. Shrimp quality is determined through handling procedures and cold chain management. Many of the target goals set in the initial SOP could not be consistently achieved. The time it took to sort shrimp from bycatch was variable and dependent on multiple factors including tow time, bycatch composition, and deckhands sorting. Despite the variability observed, minimizing sorting time should be a primary goal. A study examining bycatch mortality in the shrimp industry found that bycatch separation time was the most important variable associated with survival (Colura and Bumguardner 2001). The salinity of saltboxes varied greatly as well, and past recommendations have promoted the standardization of salt box protocols (Guillory et 
al. 2001). Tow times on skimmer boats are legally restricted to 55 minutes during October (Bourgeois et al. 2016), however, all three tows exceeded that length. The initial SOP suggested that tow times for otter trawls should be kept below three hours, but all seven trawl tows were longer. Increased tow times are associated with greater catch weight, leading to physical damage of shrimp and reduced bycatch survival (Colura and Bumguardner 2001). Strict enforcement of tow time lengths would be mutually beneficial for shrimp quality and ecological considerations. Among other areas of interest were chill tank use, rinsing, grading, and treatments used to prevent black spot. Chill tank use was inconsistent and melanosis treatment with a 4-HR product was absent. While some inconsistencies could be the result of shrimp catch being small and less valuable, an updated SOP will be necessary with more achievable targets of handling and post-harvest procedures.

The success of a brand is reliant on its reputation and market demand. The goal of LLWPFS is to consistently provide the highest quality product to those in demand. Surveys found that most chefs and managers were unaware of plate frozen technology used for shrimp, however $86 \%$ had a use for the product in their restaurant. Those that were aware of plate frozen shrimp predominately knew of LLWPFS. The estimation of order frequency and amount indicated that, on average, a single restaurant would expect anywhere from 360-585 pounds of shrimp monthly. This translates to approximately 5,684 pounds yearly, which could fetch between $\$ 30-40,000$ based on 21-25 size count plate frozen shrimp prices (T. Hymel, pers. comm.). Over half of restaurants indicated they wanted shrimp to be larger than a 20 count and nearly three quarters utilized shrimp larger than 30 count. The preferred shrimp size typically 
encompassed that caught by fishermen in the GOM. Only one respondent expected shrimp larger than a six count, which are typically not sold in the US. Wild caught white and brown shrimp rarely reach sizes of this magnitude, and the largest classification is typically size 10 and under (Bourgeois et al. 2016). Additionally, restaurants preferred five, ten and twenty pound packages, which are the current sizes most frequently used by plate freezing fishermen.

Melanosis experiments demonstrated the importance of 4-HR as an alternative additive to reduce black spot. Despite being around for decades, many fishermen are unaware of 4-HR products. Regardless of packaging type, shrimp treated with a 4-HR product remained acceptable for the entire study period. Melanosis analysis was not carried out beyond ten days post-thaw, as it is unlikely consumers would store raw shrimp for longer periods of time. All untreated samples reached objectionable levels by grading standards within three days of thawing (USDC 2011). Multiple studies have found similar results. Otwell et al. (1992) found 4-HR products to delay melanosis for 14 days of ice storage. lyengar et al. (1991) and Montero et al. (2004) also found 4-HR to inhibit melanosis at low concentrations. Additionally, there was no effect of vacuumpackaging or MAP in delaying melanosis. Previous studies have reported mixed results of packaging style on black spot prevention. In one study, the combination of frozen storage and MAP, especially with $100 \% \mathrm{~N}_{2}$ gas, inhibited melanosis for six months in frozen samples. The same study found vacuum-packaging to be ineffective (Bono et al. 2012). Another study found vacuum-packaging delayed melanosis development on tiger prawns, Penaeus japonicus, for up to 21 days sealed in refrigeration (Lopez-Caballero et al. 2000). The effectiveness of packaging in this study, within each storage interval, 
was likely lost due to the methodology used. Both vacuum-packaging and MAP seals were broken when shrimp were thawed and transferred to coolers for scoring. Although, no packaging effect was observed, average melanosis scores were significantly higher between frozen storage periods. This indicates that, while package seals were intact, MAP did not delay black spot formation through frozen storage. MAP machines are expensive making them an unlikely cost-effective solution or viable option for fishermen.

The advantages of $4-\mathrm{HR}$ products significantly outweigh disadvantages. It is effective at concentrations 250 times lower than sulfites (lyengar et al. 1991). Functionality does not improve with excess use, and residual compound levels remain low, at 1-2 ppm (lyengar et al. 1991, Otwell et al. 1992). Sulfites are commonly used in excess as they have the ability to bleach out black spots that have already formed on shrimp, leading to high residual levels (lyengar et al. 1991). It is a much safer compound than metabisulfites, for both consumers and fishermen. Sulfite powders release sulfur dioxide fumes when reacted with water (Miget 2010), which has caused death in shrimp holds in the past (Atkinson et al. 1993). For consumers, residual sulfite can elicit reactions in asthmatics and those with food sensitivities (Collins-Williams 1983, Miget 2010). The nature of adverse reactions is often dependent on consumer sensitivity and residual sulfite levels (Taylor et al. 1988). The FDA currently prohibits residual sulfites from exceeding 100 ppm (FDA 2001). Finally, 4-HR use does not deteriorate shrimp quality. Recent dissertation work found that 4-HR application did not affect the proximate composition, microbiological assessment, color analysis or texture of white or brown shrimp (Khan 2018). A potential deterrent to purchasing 4-HR products is that the compound is slightly more expensive than sulfites. A study by 
Slattery and Musgrove (2010) in Australia reported the price of EverFresh ${ }^{\circledR}$ to be $\$ 0.128 / \mathrm{kg}$ while sulfites costed approximately $\$ 0.04 / \mathrm{kg}$. Despite being more expensive, 4-HR is effective at lower concentrations, resulting in less use, and effective for longer periods of time.

Analysis of plate frozen shrimp quality demonstrated its potential to satisfy a premium head-on market. Frozen shrimp from collaborating fishermen were analyzed for physical composition and damage, residual sulfites, microbiology and melanosis development. The composition of shrimp samples was, on average, $78.0 \%$ moisture and $2.05 \%$ sodium chloride. These values are comparable to a study by Lee et al. (2002), which found moisture and salt content of a different shrimp species, Acetes chinensis, to be $77.5 \%$ and $2.3 \%$, respectively. Salt content of shrimp varies greatly in the literature. Studies on cold water shrimp, Pandalus borealis, report values of $1.0 \%$ (Gudjónsdóttir et al. 2011) and 0.5-2.5\% (Zeng et al. 2005). Reported values for farmed pacific white leg shrimp, Litopenaeus vannamei, range from $3-4 \%$ in one study (Rattanasatheirn et al. 2008) to 1.0-1.5\% in another (Chantarasuwan et al. 2011). Moisture contents are more consistent in the literature, and studies using GOM white shrimp, Litopenaeus setiferus, found moisture content to be approximately $77.3 \%$ (Khan 2018). It is apparent that seawater, cooling processes, and freezing conditions can affect these values, therefore, results should be interpreted with caution.

The physical condition shrimp is an extremely important aspect of quality for high-end restaurants utilizing a head-on shrimp product. Shrimp maintained shape and all appendages through the freezing process. Of the physical characteristics analyzed, very few of the packages would result in defect points based on USDC grading 
standards (USDC 2011). Less than one percent of all shrimp were damaged, inadvertently peeled, or missing heads in most packages. Two packages were slightly more damaged, but they were in frozen storage for over a year, which likely contributed to the decline in quality. Most shrimp packages fell on the smaller size of labelled range, however $40 \%$ of packages contained shrimp outside of the low end of the indicated size range. Larger shrimp are considered more valuable and consumers expect shrimp to be properly sized when purchasing product. It is recommended that fishermen take a conservative approach when sizing shrimp, and new size count procedures are currently being explored.

Microbiology analysis also indicated plate frozen shrimp were of high quality. The composition of microorganisms depends on a variety of conditions but is influenced by handling procedures and cold chain management. High microbial activity is the top cause for quality degradation in shrimp (Vanderzant et al. 1970), and it is suggested that high bacterial counts in frozen shrimp indicates poor quality at the time of freezing (Fieger and Friloux 1954). The International Commission on Microbiological Specification for Foods recommends that APC levels should remain below $10^{6} \mathrm{CFU} / \mathrm{g}$ for good quality (ICMSF 1986). APC values of plate frozen shrimp averaged $3.0 \times 10^{4}$ CFU/g, with only a sample exceeding $10^{5}$. An analysis of frozen shrimp purchased across the United States found APC values to average approximately $3.0 \times 10^{5}$ (Swartzentruber et al.1980), nearly double that of the highest value detected in this study. Total coliform values were found to be low in most samples and averages were comparable to other studies (Swartzentruber et al. 1980). The variability of microbiological data, within each source, is likely a result of packages being purchased 
at different times, with slightly different handling procedures occurring in the cold chain management process.

Melanosis results of plate frozen shrimp reflected the lack of consistency in operating procedures observed onboard. Half of the samples developed objectionable black spot by day three, indicating improper or absence of treatment with a 4-HR product. Although additive type and use was unknown, a lack of color change on dye tests also indicated that all plate frozen shrimp samples contained little to no residual sulfites. It is assumed that the other half of samples were properly treated with 4-HR, as they remained at acceptable levels for the duration of analysis. These studies highlight the importance of 4-HR as an effective alternative for sulfite inhibition, as well as the need to standardize protocols on shrimp boats.

Consumer awareness of social and ecological issues associated with fishery products has increased in the past few decades as fisheries are collapsing (Jacquet and Pauly 2007). LLWPFS fared well in most quality assessments and would be considered a high-quality shrimp product based on USDC/NOAA Seafood Inspection Grades (USDC 2011). Plate freezing technology gives fishermen the ability to rapidly freeze their catch and hold onto it until prices rise. Surveys indicate that there is a need for a premium head-on shrimp product in the restaurant industry. Selling direct to restaurants and consumers may give fishermen the economic boost to remain in an industry that has been of cultural importance to Louisiana for over a hundred years. Despite laws requiring shrimp packages to be labelled with potential sulfite use (FDA, 2001), the ability to guarantee a sulfite-free product, that won't develop severe melanosis, would be of great interest to consumers nationwide. LLWPFS is mutually beneficial to 
fishermen and consumers. With proper SOP updates and policing, LLWPFS has the ability to consistently provide the best quality shrimp product available to consumers, while fetching top dollar for fishermen. Pressure from foreign imports will continue to rise, and making more money for the same product might be the only solution to the resiliency of the Louisiana commercial shrimp industry.

\subsection{References}

AOAC. 1984. Official Methods of Analysis. 14 ${ }^{\text {th }}$. Ed., Washington, DC. Association of Official Analytical Chemists 330-352.

Asche, F., L. S. Bennear, A. Oglend, and M. D. Smith. 2012. US shrimp market integration. Marine resource economics 27(2):181-192.

Atkinson, D. A., T. C. Sim, and J. A. Grant. 1993. Sodium metabisulfite and SO2 release: an under-recognized hazard among shrimp fishermen. Annals of allergy 71(6):563-566.

Bono, G., C. V. Badalucco, S. Cusumano, and G. B. Palmegiano. 2012. Toward shrimp without chemical additives: A combined freezing-MAP approach. LWT-Food Science and Technology 46(1):274-279.

Bourgeois, M., K. Chapiesky, L. Landy., J. Lightner, J. Marx. 2016. Louisiana Shrimp, in Fishery Management Plan; Louisiana Department of Wildlife and Fisheries: Baton Rouge, LA; pp 1-158.

Brayden, W. C., C. L. Noblet, K. S. Evans, and L. Rickard. 2018. Consumer preferences for seafood attributes of wild-harvested and farm-raised products. Aquaculture Economics \& Management 22(3):362-382.

Chantarasuwan, C., S. Benjakul, and W. Visessanguan. 2011. Effects of sodium carbonate and sodium bicarbonate on yield and characteristics of Pacific white shrimp (Litopenaeus vannamei). Food science and technology international 17(4):403-414.

Collins-Williams, C. 1983. Intolerance to additives. Annals of allergy 51(2 Pt 2):315.

Colura, R. L., and B. W. Bumguardner. 2001. Effect of the salt-box catch-bycatch separation procedure, as used by the Texas shrimp industry, on short-term survival of bycatch. Fishery Bulletin 99(3):399-399. 
Food and Agricultural Organization (FAO). 2018. Globefish Highlights - A Quarterly Update on World Seafood Markets. April 2018 issue, with Annual 2017 Statistics.

Food and Drug Administration (FDA). 2001. Food \& Color Additives. Ch. 19. In Fish and Fishery Products Hazards and Controls Guidance, 3rd ed., p. 237-248. Food and Drug Administration, Center for Food Safety and Applied Nutrition, Office of Seafood, Washington, DC.

Fieger, E., and J. Friloux. 1954. Comparison of objective tests for quality of fresh and frozen Gulf shrimp.

Gudjónsdóttir, M., Á. Jónsson, A. B. Bergsson, S. Arason, and T. Rustad. 2011. Shrimp processing assessed by low field nuclear magnetic resonance, near infrared spectroscopy, and physicochemical measurements-The effect of polyphosphate content and length of prebrining on shrimp muscle. Journal of Food Science 76(4):E357-E367.

Guillory, V., H. M. Perry, and S. VanderKooy. 2001. The blue crab fishery of the Gulf of Mexico, United States: a regional management plan. Gulf States Marine Fisheries Commission.

International Commission on Microbiological Specifications for Foods (ICMSF). 1986. Microbial Ecology of Foods, Vol 2. Food Commodities. Academic Press, New York.

lyengar, R., C. W. Bohmont, and A. J. Mcevily. 1991. 4-Hexylresorcinol and prevention of shrimp blackspot: residual analyses. Journal of food composition and analysis 4(2):148-157.

Jacquet, J. L., and D. Pauly. 2007. The rise of seafood awareness campaigns in an era of collapsing fisheries. Marine Policy 31(3):308-313.

Khan, M. 2018. Quality of United States and Bangladesh shrimp due to growth and post-harvest practices. Louisiana State University.

Keithly Jr, W. R., and P. Poudel. 2008. The Southeast USA shrimp industry: issues related to trade and antidumping duties. Marine resource economics 23(4):459483.

Kolbe, E. R. 2004. Chilling and freezing guidelines to maintain onboard quality and safety of Albacore tuna.

Lee, K., H. Ahn, C. Jo, H. Yook, and M. Byun. 2002. Production of low salted and fermented shrimp by irradiation. Journal of Food Science 67(5):1772-1777. 
López-Caballero, M., M. Pérez-Mateos, J. Borderias, and P. Montero. 2000. Extension of the shelf life of prawns (Penaeus japonicus) by vacuum packaging and highpressure treatment. Journal of food protection 63(10):1381-1388.

Miget, R. J. 2010. Shellfish Handling Practices: Shrimp and Molluscs. Southern Regional Aquaculture Center.

Mine, S., R. Chen, S. Shelby, M. Lowe. 2016. Louisiana Shrimp Value Chain: Price Dynamics, Challenges and Opportunities. Datu Research. October 2016.

Montero, P., O. Martínez-Álvarez, and M. d. C. Gómez-Guillén. 2004. Effectiveness of onboard application of 4-hexylresorcinol in inhibiting melanosis in shrimp (Parapenaeus longirostris). Journal of Food Science 69(8):C643-C647.

National Oceanic and Atmospheric Administration - National Marine Fisheries Service. (2019). Commercial Fisheries Statistics. Retrieved May 2019 from https://www.st.nmfs.noaa.gov/commercial-fisheries/commercial-landings/annuallandings/index.

Otwell, W. S., R. Iyengar, and A. J. McEvily. 1992. Inhibition of shrimp melanosis by 4hexylresorcinol. Journal of Aquatic Food Product Technology 1(1):53-65.

Pham, D. K., J. Chu, N. T. Do, F. Brose, G. Degand, P. Delahaut, E. De Pauw, C. Douny, K. Van Nguyen, and T. D. Vu. 2015. Monitoring antibiotic use and residue in freshwater aquaculture for domestic use in Vietnam. EcoHealth 12(3):480-489.

Rattanasatheirn, N., S. Benjakul, W. Visessanguan, and K. Kijroongrojana. 2008. Properties, translucence, and microstructure of Pacific white shrimp treated with mixed phosphates as affected by freshness and deveining. Journal of Food Science 73(1):S31-S40.

Ruiz, V. 2012. Analysis of existing refrigeration plants onboard fishing vessels and improvement possibilities. Second International Symposium on fishing vessel Energy Efficiency.

Slattery, S., and R. Musgrove. 2010. Prawn industry black spot management: problem size and appropriate research.

Swartzentruber, A., A. Schwab, A. Duran, B. Wentz, and R. Read. 1980. Microbiological quality of frozen shrimp and lobster tail in the retail market. Appl. Environ. Microbiol. 40(4):765-769.

Tabarestani, M., W. R. Keithly Jr, and H. Marzoughi-Ardakani. 2017. An Analysis of the US Shrimp Market: A Mixed Demand Approach. Marine resource economics 32(4):411-429. 
Taylor, S. L., R. K. Bush, J. C. Selner, J. A. Nordlee, M. B. Wiener, K. Holden, J. W. Koepke, and W. W. Busse. 1988. Sensitivity to sulfited foods among sulfitesensitive subjects with asthma. Journal of allergy and clinical immunology 81(6):1159-1167.

Tsironi, T., E. Dermesonlouoglou, M. Giannakourou, and P. Taoukis. 2009. Shelf life modelling of frozen shrimp at variable temperature conditions. LWT-Food Science and Technology 42(2):664-671.

United States Department of Commerce (USDC). 2011. United States Standards for Grades of Fresh and Frozen Shrimp, USDC/NOAA/Seafood Inspection Program.

Vanderzant, C., E. Mroz, and R. Nickelson. 1970. Microbial flora of Gulf of Mexico and pond shrimp. Journal of Milk and Food Technology 33(8):346-350.

Zeng, Q. Z., K. A. Thorarinsdottir, and G. Olafsdottir. 2005. Quality changes of shrimp (Pandalus borealis) stored under different cooling conditions. Journal of Food Science 70(7):s459-s466. 


\section{CHAPTER 3. THE EFFECT OF SALTBOXES ON SHRIMP AND BYCATCH IN THE LOUISIANA SHRIMP FISHERY}

\subsection{Introduction}

The Louisiana commercial shrimp fishery consistently leads all other states in wild caught shrimp landings. White shrimp, Litopenaeus setiferus (Linnaeus 1767), and brown shrimp, Farfantepenaeus aztecus (Ives, 1891), comprise most landings, and these two species alone were worth $81 \%$ of country's shrimp value at over $\$ 450$ million in 2017 (NOAA 2019). Commercial gear sales indicate that otter trawls were the predominant catch method until 2006, when skimmer net license sales surpassed trawls (Bourgeois et al. 2016). Trawling is still a major part of Gulf of Mexico (GOM) and South Atlantic shrimp fishery, but is one of the least selective fishing methods (Diamond 2004). Bycatch, or non-targeted catch is often discarded either dead or alive and can be substantial in quantity and diversity. One study reports that nearly five billion croaker may die in a single year from shrimp trawls (Nichols et al. 1990), while others report over 105 different species of fish caught as bycatch (Keiser 1976). Direct mortality of bycatch, as well as indirect ecosystem degradation effects, has made trawling one of the most controversial topics in fisheries management (Murray et al. 1992, Diamond 2004). Bycatch evokes issues on economic, ethical and ecological scales and has been the topic of much research (Diamond 2004).

Bycatch removal is often referred to as culling in the shrimp industry. A popular method to assist in the culling procedure is through the use of a saltbox. Saltboxes are hypersaline tanks containing seawater and food-grade salt, commonly used aboard shrimp vessels (Colura and Bumguardner 2001). The primary use is to help speed up the separation procedure, as shrimp quality is often determined through the cold chain 
management process (Fieger and Friloux 1954). As catch is hauled onto the deck of a ship, the unsorted mixture is typically transferred to a saltbox where the shrimp and crabs sink to the bottom and a portion of the finfish bycatch floats to the top. The floating portion of bycatch can be scooped with a dip net and returned overboard. The remaining catch is then transferred to a sorting table where any leftover bycatch is sorted by hand.

There is little historical literature on the use of saltboxes. The first mention appears in the Gulf States Marine Fisheries Commission summary of marine fishing laws. They note that it is illegal in Mississippi for both recreational and commercial shrimp fishermen to use saltboxes. However, they define saltboxes as "... any container or similar device in which the salinity is greater than (100) parts per thousand and is used to aid in separating the shrimp from bycatch" (GSMFC 1993). For the purposes of this research, a saltbox will be defined as any hypersaline tank used to sort shrimp from bycatch, regardless of salinity. There are no other current regulations or recommendations towards best practices for saltbox use.

In 1997, the use of saltboxes in the Texas bay shrimp industry was characterized via interviews by Bumguardner and Colura (1997) of the Texas Parks and Wildlife Department. They found that $37 \%$ of bay shrimpers used saltboxes, but the per bay use ranged from $0-100 \%$. Saltbox size ranged from $320 \mathrm{~L}$ to $2500 \mathrm{~L}$, and the typical salinity ranged from 35-92 ppt, with an average of $67 \mathrm{ppt}$. The estimated time saved using a saltbox ranged from $20-89 \%$ with an average of $65 \%$ for bay shrimpers. The most common reasons for shrimpers not to use a salt-box was that they didn't need them, thought they were illegal, or they used it as a live box for bait shrimp or fish. They also 
found that some fishermen chose not to use saltboxes because they were concerned with bycatch mortality and others thought they could reduce shrimp quality (Bumguardner and Colura 1997).

Observations via onboard trips with Louisiana shrimp fishermen in 2017 yielded similar observations (Section 2.3.1.). The use of a saltbox sped up the sorting procedure, and salinities ranged from 47-73 ppt. Sorting times ranged from 43-120 minutes, however sorting times are highly variable and dependent on size of catch, amount of bycatch, and number of deckhands assisting in sorting.

The use of a saltbox alone does not help sort crabs from shrimp, as invertebrates typically remain on the bottom with shrimp. Two alternative strategies have been reported that may assist in sorting shrimp from crabs. One Louisiana fisherman reported that many fishers put sulfites, commonly used to inhibit black spot in shrimp, into the saltbox to make crabs swim to the surface, where they can be scooped out with a net. Sulfites are chemical scavengers and when reacted with dissolved oxygen, sodium sulfate is formed (Cavano 2007, Zupanovich 2002). This reaction starves the water of oxygen and causes crabs to swim to the top of the saltbox to retrieve oxygen from the surface. The second strategy reported was that fishermen would sometimes use two saltboxes, one to separate shrimp and crabs from finfish, and another to separate shrimp from crabs. The second saltbox would be approximately twice the salinity to make the shrimp float and the crabs remain on the bottom. Shrimp fishermen also add other various chemicals to saltboxes to increase the gravity of the liquid, which in turn, is said to kill all bycatch (Adkins 1993). 
A previous study found blue crabs to be one of the most durable bycatch species in the shrimp industry, based on 48-hour bioassays using high salinity seawater. They found minimal effects of saltbox use on short-term, within 48 hours of catch, survival of all bycatch species (Colura and Bumguardner 2001). However, there is concern by blue crab fishermen of juvenile crab mortality due to the use of saltboxes (J.Lively, pers. comm.). Guillory et al. (2001) also suggested that saltbox use to separate bycatch may contribute to juvenile blue crab mortality with increases in delayed mortality resulting from prolonged dips. One of the recommendations of the 2001 blue crab regional fishery management plan was to "Encourage adaption of bycatch separation practices that reduce non-directed fishing mortalities", with a goal to standardize saltbox protocols (Guillory et al. 2001).

The use of saltboxes in the industry has been a continual debate for managers. Studies have found conflicting results, and some managers propose the elimination of saltboxes (Adkins 1993), while others are proponents for its use (Colura and Bumguardner 2001). The goal of this research is to examine the effects saltboxes may have on blue crab bycatch mortality and shrimp quality, while determining best uses to promote sorting efficiency, saving fishermen time and money. There were three main objectives of this study: 1) determine the effect high salinity saltbox use may have on long-term survival of blue crabs, 2) examine the effect of sulfite use in saltboxes on juvenile blue crabs and 3) estimate the saltbox salinity that maximizes efficiency in sorting bycatch from shrimp and analyze subsequent effect on shrimp salt content. 


\subsection{Methods and Materials}

\subsubsection{Collection}

Blue crabs, Callinectes sapidus (Rathbun 1896), below Louisiana commercially harvestable size (<127 mm carapace width), were caught in Point Aux Chenes (PAC) Wildlife Management Area in June and July of 2018. Juvenile blue crabs ( $<40 \mathrm{~mm}$ carapace width) were caught by colleagues via trawls in Rockefeller Wildlife Refuge (RWR) in Grand Chenier, Louisiana in August of 2018. All crabs were collected for research purposes under LA collection permit \#SCP 28. Crabs were caught using dip nets in seawater of $10.5 \pm 1.0 \mathrm{ppt}$ salinity and $22.5 \pm 2.0^{\circ} \mathrm{C}$ temperature. Specimens were held in insulated ice chests containing ice and a layer of burlap to reduce direct contact with ice. The cold temperature in the cooler induced a temporary dormant state in the crabs preventing conspecific aggression. Crabs from PAC were held in individually numbered cages and acclimated in a $1200 \mathrm{~L}$ rectangular tank at $10.5 \pm 1.0$ ppt salinity seawater for 10 days. Juvenile blue crabs from RWR were acclimated in an $800 \mathrm{~L}$ cylindrical tank at the same salinity seawater for two weeks. Any crabs that did not return to normal state were presumed dead and disposed of.

\subsubsection{Blue Crab Survival}

Three experimental saltboxes were made using $70 \mathrm{~L}$ cylindrical tanks, to mimic saltboxes onboard shrimping vessels. The water used in saltboxes was adjusted to three salinity levels for experimentation: $\mathrm{S} 35=35 \mathrm{ppt}, \mathrm{S} 60=60 \mathrm{ppt}$, and $\mathrm{S} 80=80 \mathrm{ppt}$ made with Sea and Land $\circledast$ evaporated salt commonly used by shrimp fishermen. Salinities were chosen as low, medium and high salinity variables representative of those documented aboard shrimp boats. Blue crabs and their respective cage were 
removed from the acclimation tank at random and placed into saltboxes for varying durations: $\mathrm{T} 1=1$ minute, $\mathrm{T} 5=5$ minutes, or $\mathrm{T} 10=10$ minutes. Upon completion of the dip, each crab and cage were transferred to individual $40 \mathrm{~L}$ static tanks for long-term observation. Five control crabs were transferred directly from the acclimation tank to the observation tanks. Observation tanks were set at $10.5 \mathrm{ppt}$ with a constant air supply and 12:12 light dark cycle. Experimentation was conducted in June and July of 2018. A total of 10 treatment groups were analyzed with 5 replicates in each (Table 3.1).

Table 3.1. Treatment and control variables used to test the survival of blue crabs being dipped in saltboxes $(n=5)$.

\begin{tabular}{ccc}
\hline Treatment & Salinity (ppt) & Time $(\min )$. \\
\hline Control & 10.5 & Constant \\
S35T1 & 35.0 & 1 \\
S35T5 & 35.0 & 5 \\
S35T10 & 35.0 & 10 \\
S60T1 & 60.0 & 1 \\
S60T5 & 60.0 & 5 \\
S60T10 & 60.0 & 10 \\
S80T1 & 80.0 & 1 \\
S80T5 & 80.0 & 5 \\
S80T10 & 80.0 & 10 \\
\hline
\end{tabular}

Blue crabs were observed daily for 30 days following treatment. Crabs were fed bait shrimp three times per week in secondary tanks to prevent water quality degradation. Water quality was assessed after feedings, and nitrites $\left(\mathrm{NO}_{2}^{-}\right)$and ammonia were maintained below $0.25 \mathrm{mg} / \mathrm{L}$. If water quality tests failed, complete water changes were performed. Water was maintained at $10.5 \pm 1.0 \mathrm{ppt}$ salinity and water temperature was recorded using a temperature logger (Onset Tidbit version 2). All salinity levels were measured using a Model 30-10FT YSI meter. Crab excrement was removed during feeding intervals by siphoning. Molting behavior of crabs was recorded, 
and molts were removed from the tank. The date of crab mortality was recorded, and carapace width was recorded.

\subsubsection{Incorporating Sulfites into Saltboxes}

To examine if sulfites, in combination with salinity, affected juvenile blue crab survival, saltboxes $(18.9 \mathrm{~L}$ tanks) were made using $1 \times$ concentration $(11.98 \mathrm{~g} / \mathrm{L})$ of sulfites (1S) as recommend for black spot inhibition or no sulfite (control sulfite; CS) at 10.5 ppt (control; Sa10.5) or 80 ppt (experimental; Sa80) salinity (Table 3.2). A maximum experimental salinity was chosen for this study to induce the most stressful conditions that may occur on shrimp boats. The amount of sulfite used by fishermen is unknown, however a $1 \mathrm{x}$ concentration was chosen as excess would likely cause detectable limits in shrimp samples. The carapace width (CW) of crabs was recorded, and each crab was placed in a saltbox for 5 minutes. Juvenile crabs were then removed and placed in individual $2 \mathrm{~L}$ tanks. Crabs were monitored over the course of two weeks, and molting occurrences were recorded. Water quality was assessed regularly and maintained via siphoning excrement, water changes, and removing molts. There were six replicates for each treatment with a total of 24 crabs used for the experiment.

Table 3.2. Treatment and control variables used to test the survival of blue crabs being dipped in saltboxes containing sulfites $(n=6)$. CS represents sulfite control and 10.5/ 35 represents salinity control, while $S 1$ represents $1 x$ sulfite treatment and 80 represents elevated salinity treatment.

\begin{tabular}{ccc}
\hline Treatment & Salinity (ppt) & Sulfite Conc. \\
\hline CS-Sa10.5 & 10.5 & $0 \mathrm{x}$ \\
CS-Sa80 & 80.0 & $0 \mathrm{x}$ \\
1S-Sa10.5 & 10.5 & $1 \mathrm{x}$ \\
1S-Sa80 & 80.0 & $1 \mathrm{x}$ \\
\hline
\end{tabular}




\subsubsection{Sorting Efficiency and Effect on Salt Content}

Collection and Setup

A fresh haul of shrimp and bycatch (all dead) was purchased from a commercial shrimp fisherman and stored in a seawater and ice mixture for less than 24 hours until experiments were conducted. The mixture was not sorted, therefore was not exposed to a saltbox onboard. Saltboxes (70 L; see section 3.2.2.) were set up on a dock in Terrebone Parish, Louisiana, where experiments were conducted. Seawater from the canal was added to the saltboxes and Land and Sea ${ }^{\circledR}$ fishermen grade evaporated salt was added to achieve the desired salinities: $35.0,60.0$, and $80.0 \pm 1.0$ ppt. Water temperature and salinity at the dock was recorded, however they were not able to be collected from time of catch. Water temperature was likely similar to time of catch; however, salinity was likely lower as the dock was located further inland than most fishing locations. Bycatch species were identified down to the lowest possible taxonomic level.

\section{Experimental Design}

Saltbox experiments mimicked commercial vessel conditions where $6.8 \mathrm{~kg}$ of the shrimp and bycatch mixture was chosen at random, weighed, and poured into one of three saltboxes. The mixture was stirred for one minute, and let sit for two additional minutes, similar to observed procedures on commercial shrimp fishing trips. All bycatch floating on the surface was skimmed off using a dip net and weighed. The remaining bycatch and shrimp on the bottom was then sorted and weighed separately. A surface and bottom weight of both bycatch and shrimp was recorded and the total weight of each and ratio of floating bycatch to bottom bycatch was determined. This procedure 
was repeated three times for each saltbox, and a new bycatch/shrimp mixture was used for each replicate. Five to seven shrimp were saved at the end of each replicate and returned to the lab for salt content analysis via the Volhard back-titration method (Section 2.2.4.). Control shrimp were not dipped in saltboxes prior to salt content analysis. Salt content was determined as a percentage of chlorine, as sodium chloride, $(\% \mathrm{NaCl})$ in each sample (AOAC 1984).

\section{Statistics}

Statistics were conducted using Statistical Analysis Software (SAS Version 9.4). To analyze the effect of saltbox salinity on sorting efficiency, a simple linear regression was conducted between the dependent variable, ratio of floating bycatch to total bycatch weight, and the independent variable, saltbox salinity. Analysis of Variance (ANOVA) was conducted to determine if the salinity groups were significantly different in sorting efficiency ratios. Results were further analyzed using Tukey's Honest Significant Difference (HSD) post-hoc test. To examine the effect of saltbox salinity on salt content in shrimp, a simple linear regression was conducted between the dependent variable, percentage of sodium chloride in each sample, and the independent variable, saltbox salinity. ANOVA was conducted to determine if there was any significance difference in responses by the dependent variable by saltbox salinity. Tukey's HSD post-hoc test was used to determine significance between groups. Assumptions were checked and a significance level of 0.05 was used for all analyses. 


\subsection{Results}

\subsubsection{Blue Crab Survival}

In order to determine if saltbox salinity affected blue crab survival, crabs were exposed to salinity and duration combinations. Blue crabs ranged in size from 53.5$112.5 \mathrm{~mm}$ with the average size being $83.8 \pm 17.7 \mathrm{~mm} \mathrm{CW}$. Over the course of both experimental periods only 1 of the 50 crabs died; from treatment S35T1 on day 18 of the 30 -day monitoring period. Final survival was $100 \%$ for all treatments except for S35T1, where survival was $80 \%$ (Fig. 3.1). Throughout this study, $18 \%(n=9)$ of crabs molted. At least one individual from each experimental time and salinity molted. The single mortality was one of the 9 crabs that had molted. Water temperature ranged from $21.3^{\circ} \mathrm{C}$ to $23.6^{\circ} \mathrm{C}$ and averaged $23.1^{\circ} \mathrm{C}$.

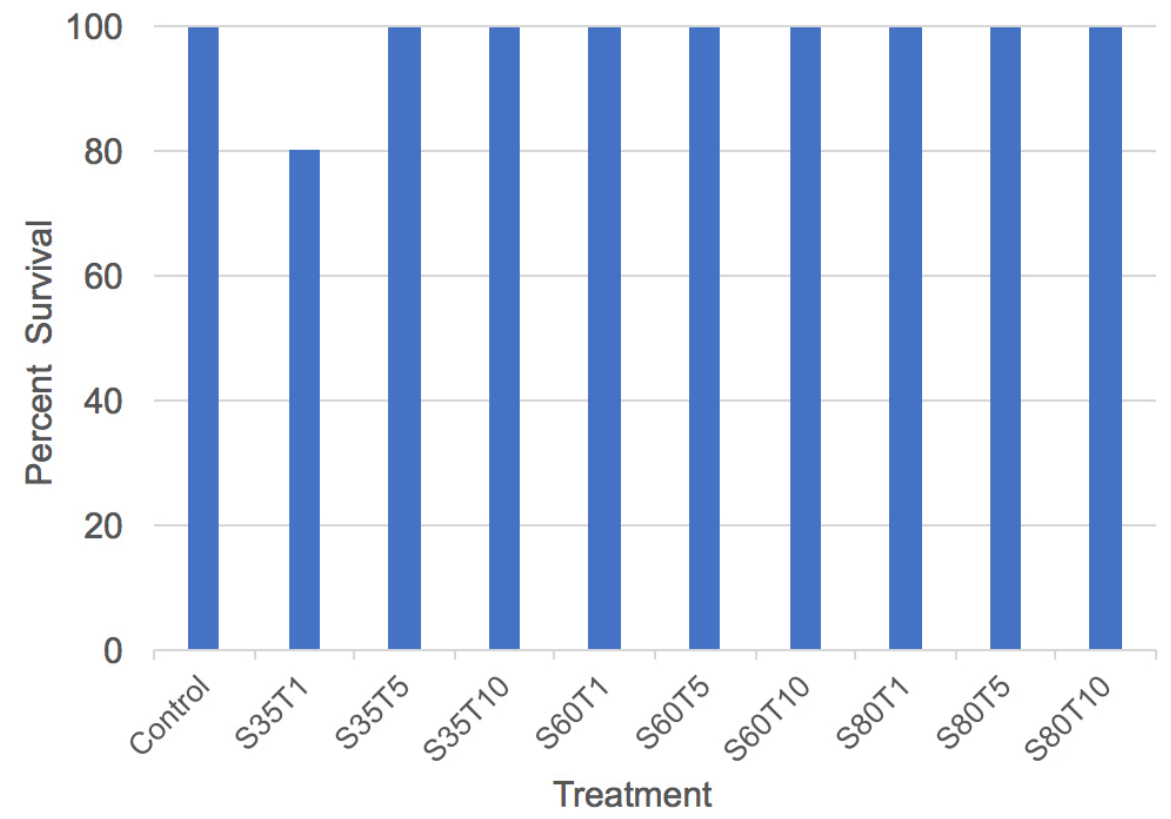

Figure 3.1. Percent survival of blue crabs per saltbox treatment. Each bar represents the percentage living after 30 days of monitoring ( $n=5$ per treatment). 


\subsubsection{Incorporating Sulfites into Saltboxes}

In order to determine if the addition of sulfite to a saltbox affected survival, juvenile blue crabs were exposed to sulfite and salinity combinations in a saltbox. Juvenile blue crabs ranged from $18.5-36.5 \mathrm{~mm}$ with an average size of $25.58 \pm 4.52$ $\mathrm{mm}$ CW. All crabs initially sank to the bottom when placed in saltboxes, and control crabs remained there for the duration of the dip. Crabs placed in saltboxes containing sulfite swam to the surface at least once within the first two minutes, then descended and remained on the bottom for the rest of the dip. Through two weeks of monitoring, 0 of the 24 crabs died. Half of the crabs molted during the study and at least two molted from each treatment. A color change was observed on the carapace of some crabs and persisted through molting (Figure 3.2). This was obseved in individuals from both control and experimental replicates.

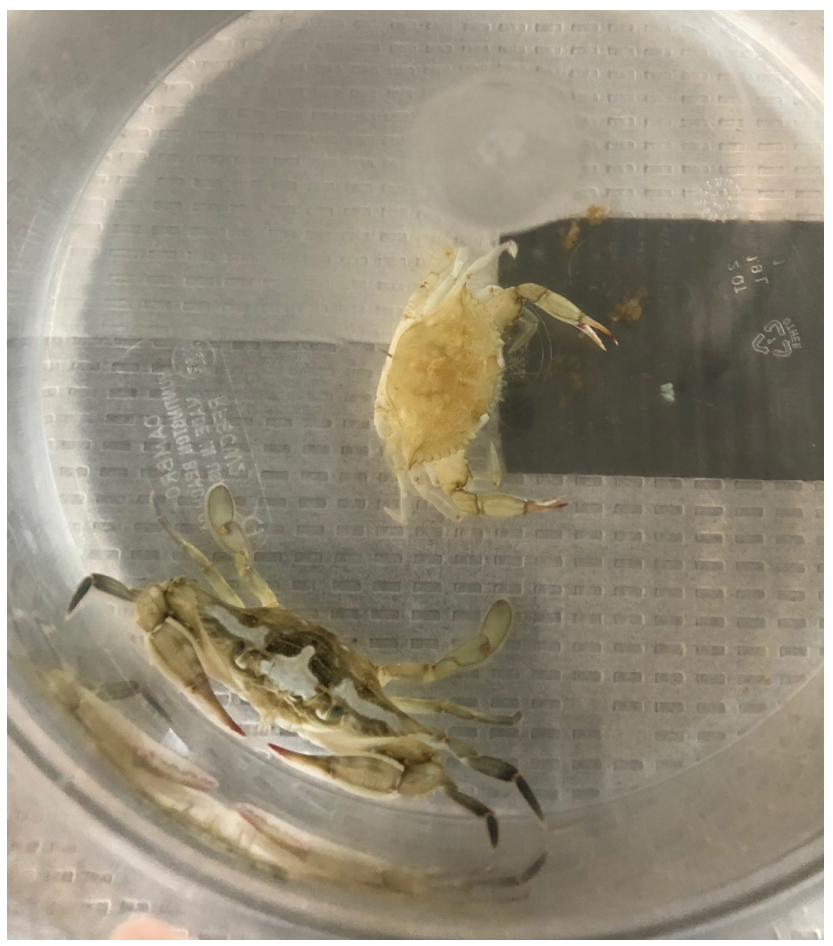

Figure 3.2. A blue crab from saltbox treatment group CS-Sa10.5 with an observed color change post-molt. 


\subsubsection{Sorting Efficiency and Effect on Salt Content}

Shrimp and bycatch mixture was purchased from a fisherman, and saltbox salinities were tested to determine if salinity affected separation of shrimp and bycatch and subsequent shrimp salt content. The catch was composed of $27.3 \mathrm{~kg}$ of shrimp and $34.0 \mathrm{~kg}$ of bycatch: an approximate shrimp:bycatch ratio of $45: 55$. The bycatch was composed of 9 species with Gulf Menhaden, Brevoortia patronus, and Atlantic Croaker, Micropogonias undulates, constituting the majority of it (Table 3.3). No shrimp were skimmed off the surface during experimentation; therefore, the surface shrimp weight statistic was eliminated as bottom weight equaled total shrimp weight.

Table 3.3. Composition of bycatch from the catch purchased by a fisherman. Bycatch was identified to the lowest recognizable taxonomic classification.

\begin{tabular}{ll}
\hline Common Name & Classification \\
\hline Gulf Menhaden & Brevoortia patronus \\
Atlantic Croaker & Micropgonias undulates \\
Spot & Leiostomus xanthrus \\
Pinfish & Lagodon rhomboids \\
Cutlassfish/Largehead hairtail & Trichiuris lepturus \\
Southern Flounder & Paralichthys lethostigma \\
Pufferfish & Sphoeroides sp. \\
Bay Anchovy & Anchoa mitchilli \\
Highfin Goby & Gobionellus oceanicus \\
\hline
\end{tabular}

The high salinity saltbox, $80 \mathrm{ppt}$, had the highest percentage of floating bycatch at $48.4 \pm 3.0 \%$. The lowest percentage, $23.2 \pm 2.7 \%$, occurred in the low salinity saltbox of $35 \mathrm{ppt}$ (Fig. 3.3). The ratio of floating bycatch between all salinity groups were statistically significant based on ANOVA $(F=69.51, P<0.0001)$. Tukey's HSD test indicated all three groups were significantly different from each other (Figure 3.3). 


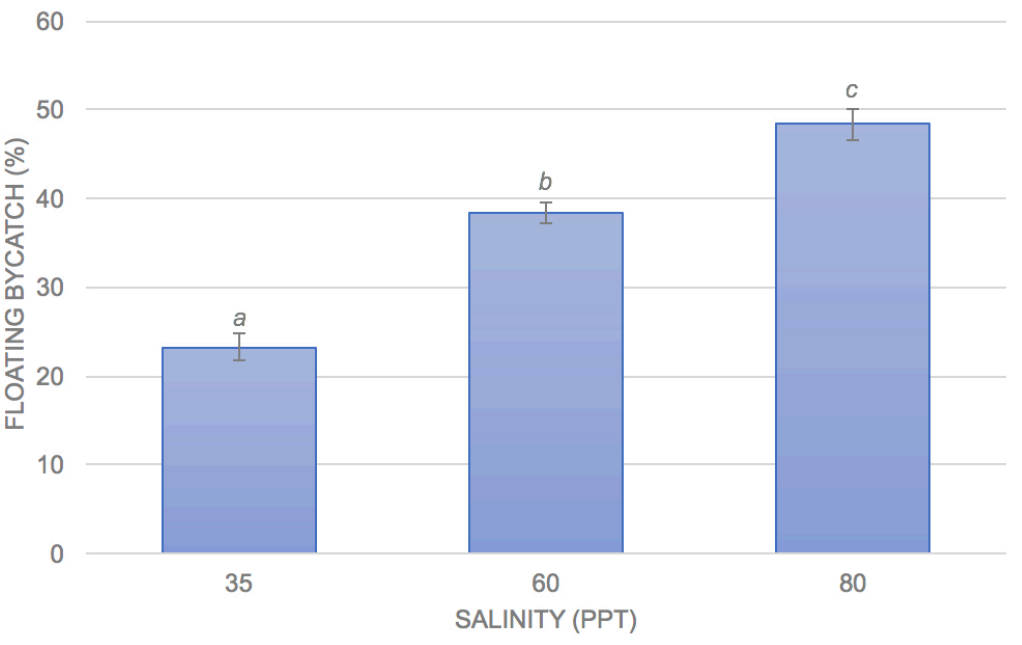

Figure 3.3. The average sorting efficiency for saltboxes of each salinity group. Efficiency was expressed as a percentage of floating bycatch after three minutes of mixing and sitting. All three groups were significant different from each other based on ANOVA ( $F=$ 69.51, $\mathrm{P}<0.0001$ ) and different letters indicate significant difference based on Tukey's HSD comparison. Error bars represent standard error within each treatment group.

Simple linear regression analysis indicated a significant relationship between sorting efficiency and saltbox salinity. ( $F=150.96, P<0.0001$, Figure 3.4). The Shapiro-Wilk test for normality indicated the residuals of the response variable were normally distributed $(P=0.6579)$.

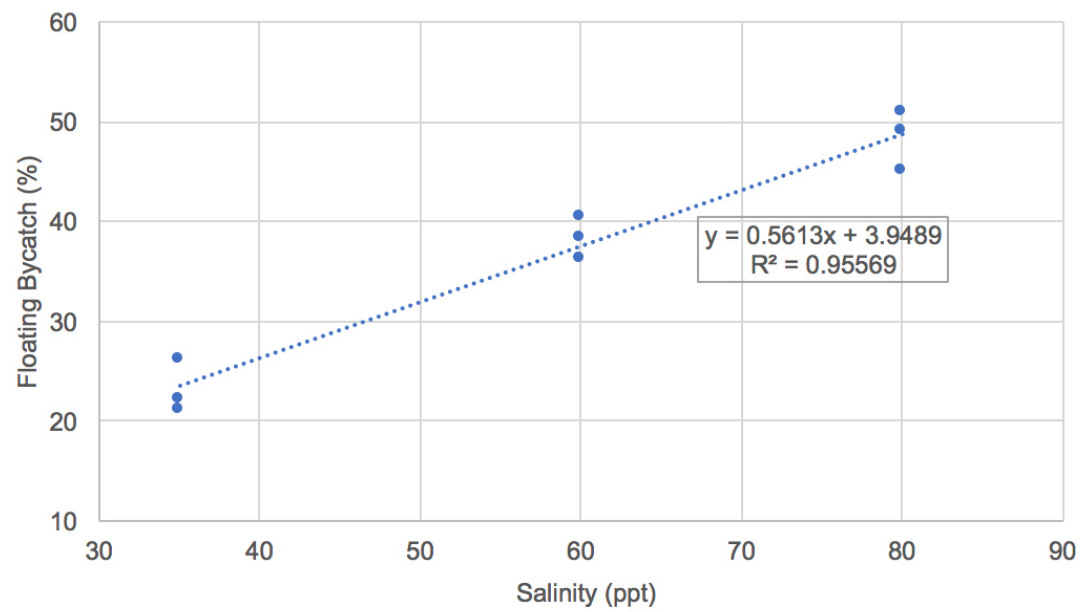

Figure 3.4. Linear regression of sorting efficiency of saltboxes by salinity groups. Efficiency was expressed as a percentage of floating bycatch after three minutes of mixing and sitting. Analysis found the slope of the line to be significantly different from zero $(F=150.96, P<0.0001)$. 
Salt content analysis determined the lowest average percent sodium chloride, at $2.56 \pm 0.18 \%$, occurred in the control group that was not dipped in any saltbox. The highest salt content occurred in the high salinity treatment group with an average of $3.35 \pm 0.36 \%$ (Figure 3.5). The salt content of control and experimental groups were not significantly different from each other (ANOVA, $F=1.97, P=0.1977$ ). Simple linear regression analysis indicated a marginally significant relationship between salinity of the saltbox and percentage sodium chloride $(F=7.26, P=0.0226$, Figure 3.6). The ShapiroWilk test for normality indicated the data was normally distributed $(P=0.9776)$.

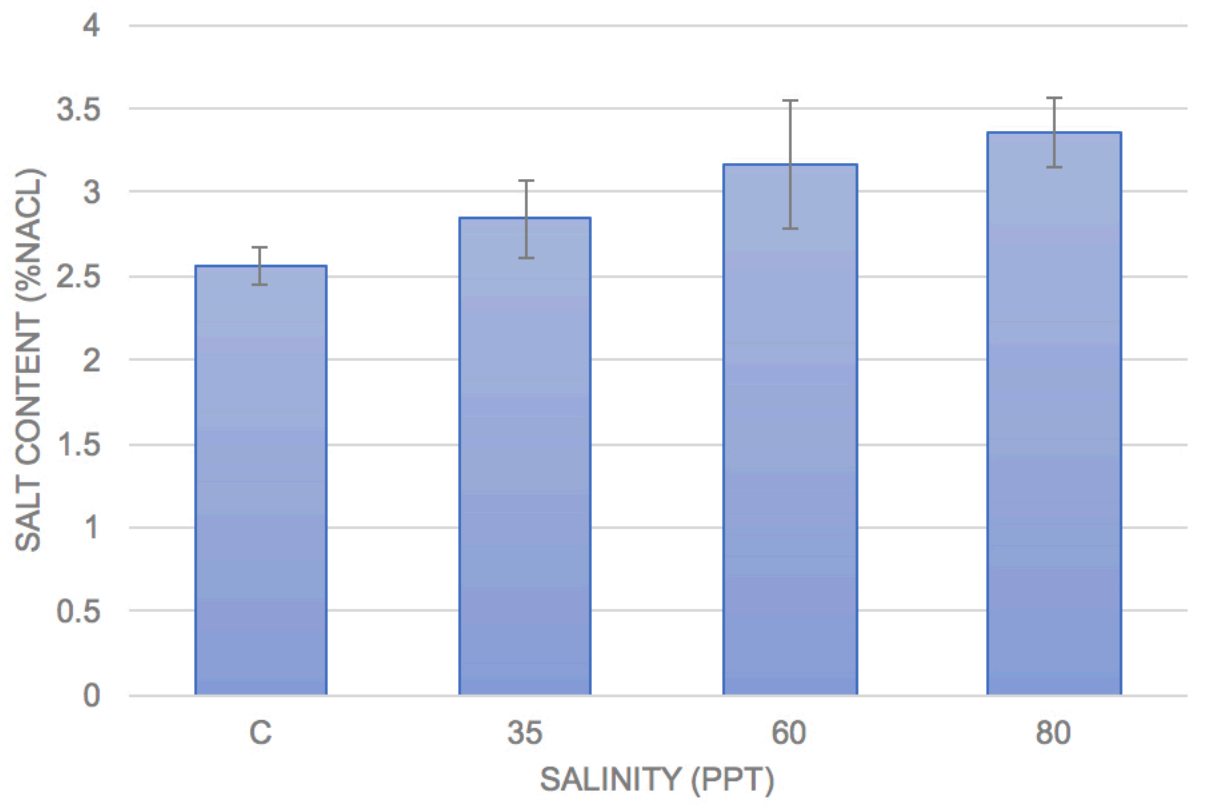

Figure 3.5. Average salt content of shrimp from saltbox trials. $\mathrm{C}=\mathrm{a}$ control baseline of shrimp that were not sorted using a saltbox. The salinity for the control group was based on salinity of seawater at the dock (3.6 ppt). There was no significance among groups. (ANOVA, $F=1.97, P=0.1977$ ). Error bars represent the standard error within each treatment group. 


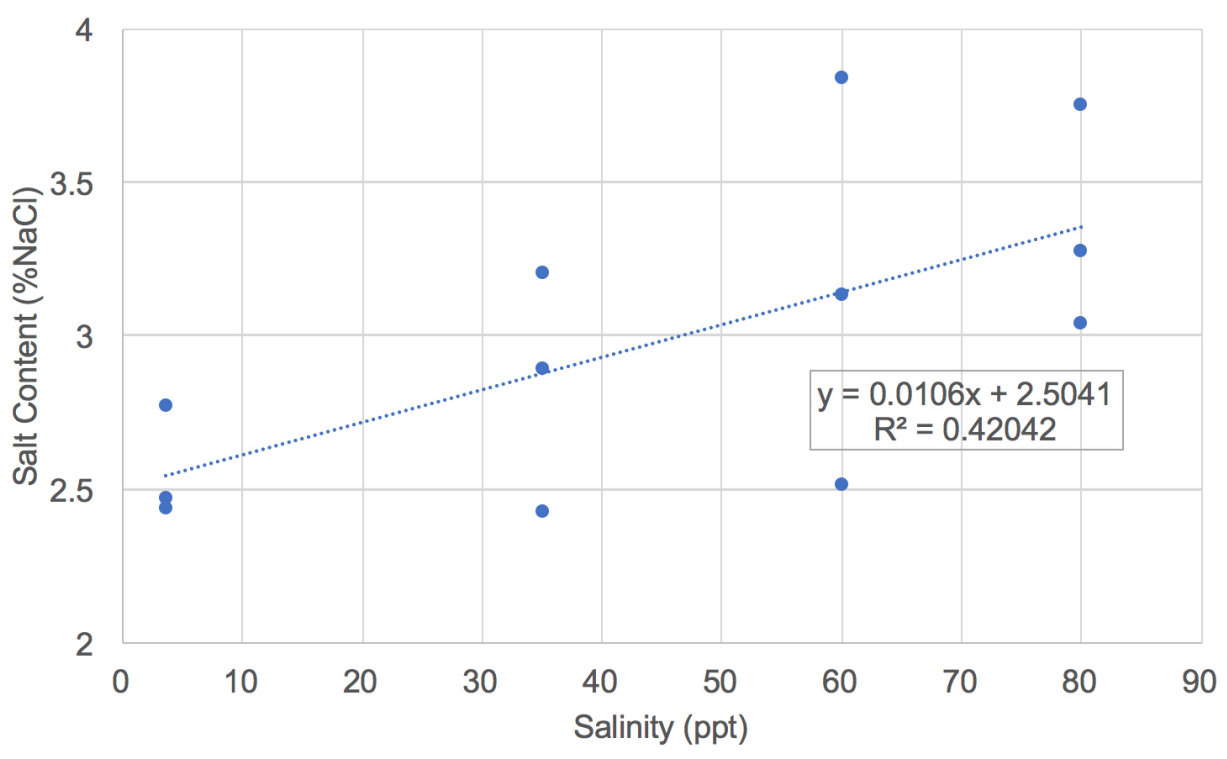

Figure 3.6. Salt content of shrimp sorted using different salinity saltboxes. The first group represents a control based on shrimp that were not sorted using a saltbox. Simple linear regression analysis found the slope of the line to be significantly different from zero $(F=7.26, P=0.0226)$.

\subsection{Discussion}

The goal of this study was to determine the effectiveness of saltbox use for bycatch separation and evaluate potential long-term effects on blue crabs. Based on past literature and personal observation, temporary saltboxes used in this study successfully emulated the conditions typically seen on shrimp boats in the GOM. Experiments were designed to investigate some of the conflicting evidence surrounding blue crab survival and to help explain the variability of salinity seen across saltboxes. Results of this study provide insight towards best practices for saltbox use, while demonstrating no effect on direct mortality of blue crabs. Maximizing culling efficiency through proper salinity choice has the potential to save fishermen time and get bycatch back into the water more quickly. 
No effect of saltbox salinity, or duration in the saltbox, was seen on long-term survival ( 30 days) of blue crabs below commercially harvestable size. Blue crabs of this size were chosen because larger crabs caught as bycatch are typically kept and often separated prior to catch being placed in a saltbox. Only one of the fifty crabs used in the experiment died and it was dipped in the lowest salinity and shortest duration group, indicating mortality was likely due to alternative reasons. These results are not surprising as blue crabs are a euryhaline species capable of tolerating a wide range of salinities (Tan and Van Engel 1966). Colura and Bumguardner (2001) conducted bioassays on five economically important bycatch species to determine the effect of saltboxes on short-term survival. Using 70 ppt seawater, juvenile blue crabs (45 \pm 4.8 $\mathrm{mm} \mathrm{CW}$ ) had the greatest $\mathrm{LE}_{50}$ of the species examined at 67 minutes, meaning it took 67 minutes to see $50 \%$ mortality. They concluded that the use of a saltbox had little to no effect on short term survival of bycatch (Colura and Bumguardner 2001). Based on personal observations onboard shrimp fishing vessels, it is unlikely that crabs would remain in a saltbox for over an hour. Typically catch is sorted and processed quickly to make room for the next haul.

Crabs were monitored for 30 days to see if long-term effects from saltbox exposure resulted in mortality. Although no direct mortality was seen in the lab, these results cannot be extrapolated to wild conditions. Stress from a rapid salinity change could cause increased susceptibility to predation or disease. A color change of the carapace was observed in some of the crabs, however this has been previously documented under laboratory conditions (Newcombe 1945, Lively and Ducote, unpublished data). If color change was associated with salinity of the saltbox, this could 
play a role in both camouflage to predators and mate choice in crabs. A study on the visual cues of blue crabs for courtship found that Callinectes sapidus is capable of color vision and use color in mate choice (Baldwin and Johnsen 2009). Further research is needed to explore the cause of this change, as well as other sublethal effects.

It is unknown whether sulfites are one of the additional chemicals added to saltboxes, as mentioned by Adkins (1993), however, Louisiana fishermen report it to be a common practice. When incorporating sulfites into saltboxes, no mortality was observed. A fisherman reported that sulfites cause juvenile blue crabs to swim to the surface and this was confirmed in the study. Within two minutes of being placed in saltboxes with sulfite, all crabs would swim to the surface at least once. They did not remain on the surface for the duration of the dip and typically descended back down to the bottom of the bucket after a few seconds. Color change was observed again and was more prevalent than in the initial blue crab survival experiment. It appeared as though crabs dipped in the experimental treatments were more likely to develop white spots on their carapace, however it occurred in control samples as well. This color change may be associated with sulfites as they have the ability to remove black spots on the exoskeleton of crustaceans, such as shrimp (lyengar et al. 1991). Black spot occurs post-mortem in shrimp due to an enzyme reaction, however it is possible that sulfites affect the natural color properties of a living blue crab. Abnormal coloration of the carapace remained post-molt. Only $1 \mathrm{x}$ concentration of sulfite was used, but it is suspected that with increased concentration, an increase in color change will occur.

Quantifying sorting efficiency was a main objective to help understand the high variability in salinities used within the industry. One fisherman reported that the salinity 
used depended on the primary bycatch species, while another fisherman reported that the amount of salt used was estimated. Determining the ratio of floating versus sinking bycatch demonstrates the efficiency in the culling procedure. The results indicated that there was a linear relationship between sorting efficiency and salinity used. Percentage of floating bycatch worked well as a proxy for sorting efficiency because no shrimp floated within the range of salinities used in the study. This proxy for efficiency needs to be interpreted with caution as an increase in salinity beyond 80 ppt would likely cause shrimp to begin to float, rendering the saltbox inefficient, as shrimp would be discarded with floating bycatch. In both the low and middle salinity treatments, the shrimp and majority of the bycatch sank to the bottom immediately when dumped into a saltbox. In the high salinity treatment, shrimp and bycatch remained on top and the shrimp slowly fell to the bottom as stirring occurred. It is suspected that if salinity was increased towards $100 \mathrm{ppt}$ shrimp would begin to float with the bycatch.

Bycatch is a global issue in fisheries and solutions to reduce unnecessary discards have been examined extensively. Kelleher (2005) estimated that nearly $50 \%$ of world bycatch discards are from finfish and shrimp trawls, with $27 \%$ resulting from tropical shrimp trawls alone. Although bycatch ratios have been reported as high as 2.5 kg in the Gulf shrimp otter trawl fishery by voluntary shrimp observer programs (ScottDenton et al. 2012), skimmer nets dominate Louisiana waters and produce less bycatch (Scott-Denton et al. 2006). The shrimp to bycatch ratio observed in this study was approximately $1.25 \mathrm{~kg}$ of bycatch per kilogram of shrimp. The gear type used to harvest the catch in this study was unknown, however the bycatch to shrimp ratio calculated is 
comparable to that of the $1.24 \mathrm{~kg}$ observed on skimmer boats in 2011 (Pulver et al. 2012).

Identifying the proper salinity for saltboxes can increase efficiency for fishermen and potentially reduce bycatch mortality by returning species to the ocean more quickly. Bycatch sorting times were not recorded, but the highest salinity group reduced the time spent culling. Surveys of Texas bay shrimpers indicated that saltboxes reduce sorting time by $65 \%$ on average (Bumguardner and Colura 1997). Colura and Bumguardner (2001) examined both environmental and procedural variables that were associated with bycatch mortality. They found that catch separation time was the variable most significantly influenced bycatch mortality, and the quicker catch is sorted, the lower the rate of mortality. (Colura and Bumguardner 2001). Many species are presumed dead at the time catch is brought on deck; however, future work could examine tradeoffs between high salinity stress from saltboxes and the reduced time out of water for species likely to still be alive during sorting. The effectiveness of saltbox use has the potential to change based on bycatch composition; therefore, additional work could examine the seasonal and spatial effects of salinity on sorting efficiency.

Shrimp from saltbox efficiency trials were analyzed to determine if subsequent salt content changes were observed between treatment groups. The sodium chloride averages for shrimp were higher than most reports for raw shrimp. The control group averaged $2.56 \%$, while the high salinity group rose to $3.35 \%$, however, the shrimp dipped into saltboxes had a wide range of salt content. Observed values in this study were higher than salt content levels determined in plate frozen shrimp samples, which averaged $2.05 \pm 0.29 \%$ (Section 2.3.4.). Lee et al. (2002) determined the salt content of 
raw shrimp, Acetes chinensis, to be approximately $2.3 \%$, which is similar to the results from this study. Other studies report the salt content of farmed pacific white shrimp, Litopenaeus vannamei, ranged from 1 - 4\% (Rattanasatheirn et al. 2008, Chantarasuwan et al. 2011), and wild caught cold-water shrimp, Pandalus borealis, ranged from 0.5-2.5\% (Zeng et al. 2005, Gudjónsdottir et al, 2011). Salt content values of the shrimp used in this study should be interpreted with caution. The literature indicates high variability in the salt content of raw and frozen shrimp, most likely based on several parameters. High salt content may be partially attributed to the time of year shrimp were caught. In September to November, salinity is typically the highest in Barataria and Terrebone Bays, where the shrimp used in this study were caught (Orlando et al. 1993). The unsorted catch was placed in refrigerated sea water on board before use. Therefore, the salinity and duration in the water may also influence salt content. Sodium content is one of the primary indicators of flavor in shrimp, and consumers typically prefer a salty flavor, to an extent, in shrimp (Sims 2013). Future studies could focus on the effect saltboxes have on sodium content in shrimp, and determine if there is a correlation with consumer preference.

Saltbox use is likely to continue to be a topic of debate amongst managers of the shrimp industry. As mentioned in "The Blue Crab Fishery of the Gulf of Mexico, United States: A Regional Management Plan", encouraging the adoption of standardized bycatch separation techniques may help contribute to bycatch survival in the future (Guillory et al. 2001). The research at hand found no long-term effect of saltbox use, with or without sulfite, on blue crab survival. Additionally, using the correct salinity can significantly reduce catch separation time, getting bycatch back in the water more 
quickly and efficiently. Saltboxes also allow for less direct handling of bycatch and reduce exposure time to air, which could enhance survival. Additional research will be needed to explore what, if any, additional chemicals are added to saltboxes. Consumers are increasingly aware of the environmental impact of their seafood choices, and quantities of dead bycatch has always been a public perception problem in the shrimp fleet. Minimizing unnecessary mortality will continue to be an important goal for management.

\subsection{References}

Adkins, G. 1993. A comprehensive assessment of bycatch in the Louisiana shrimp fishery. Louisiana Department of Wildlife and Fisheries. Technical Bulletin 42:71.

AOAC. 1984. Official Methods of Analysis. $14^{\text {th }}$. Ed., Washington, DC. Association of Official Analytical Chemists 330-352.

Baldwin, J., and S. Johnsen. 2009. The importance of color in mate choice of the blue crab, Callinectes sapidus. Journal of Experimental Biology 212(22):3762-3768.

Bumguardner, B., and R. Colura. 1997. A description of salt-box use by the Texas bay shrimp fishery. Management Data Series 140. Texas Parks and Wildlife, Coastal Fisheries Division, Austin, Texas.

Cavano, R. 2007. Sulfites for Oxygen Control. Scranton Associates, Incorporated.

Chantarasuwan, C., S. Benjakul, and W. Visessanguan. 2011. Effects of sodium carbonate and sodium bicarbonate on yield and characteristics of Pacific white shrimp (Litopenaeus vannamei). Food science and technology international 17(4):403-414.

Colura, R. L., and B. W. Bumguardner. 2001. Effect of the salt-box catch-bycatch separation procedure, as used by the Texas shrimp industry, on short-term survival of bycatch. Fishery Bulletin 99(3):399-399.

Diamond, S. L. 2004. Bycatch quotas in the Gulf of Mexico shrimp trawl fishery: can they work? Reviews in Fish Biology and Fisheries 14(2):207-237.

Fieger, E., and J. Friloux. 1954. Comparison of objective tests for quality of fresh and frozen Gulf shrimp. 
Gudjónsdóttir, M., Á. Jónsson, A. B. Bergsson, S. Arason, and T. Rustad. 2011. Shrimp processing assessed by low field nuclear magnetic resonance, near infrared spectroscopy, and physicochemical measurements-The effect of polyphosphate content and length of prebrining on shrimp muscle. Journal of Food Science 76(4):E357-E367.

Guillory, V., H. M. Perry, and S. VanderKooy. 2001. The blue crab fishery of the Gulf of Mexico, United States: a regional management plan. Gulf States Marine Fisheries Commission.

Gulf States Marine Fisheries Commission (GSMFC). 1993. A summary of marine fishing laws and regulations for the Gulf states. Ocean Springs, MS.

lyengar, R., C. W. Bohmont, and A. J. Mcevily. 1991. 4-Hexylresorcinol and prevention of shrimp blackspot: residual analyses. Journal of food composition and analysis 4(2):148-157.

Keiser, R. K. 1976. Species composition, magnitude and utilization of the incidental catch of the South Carolina shrimp fishery. Marine Resources Research Institute, South Carolina Wildlife and Marine.

Kelleher, K. 2005. Discards in the world's marine fisheries: an update, volume 470. Food \& Agriculture Org.

Lee, K., H. Ahn, C. Jo, H. Yook, and M. Byun. 2002. Production of low salted and fermented shrimp by irradiation. Journal of Food Science 67(5):1772-1777.

Murray, J. D., J. J. Bahen, and R. A. Rulifson. 1992. Management considerations for bycatch in the North Carolina and Southeast Shrimp Fishery. Fisheries 17(1):21-26.

Newcombe, C. L. 1945. The biology and conservation of the blue crab, Callinectes sapidus Rathbun. Commonwealth of Virginia, Division of Purchase and Print.

Nichols, S., A. Shah, G. Pellegrin Jr, and K. Mullin. 1990. Updated estimates of shrimp fleet bycatch in the offshore waters of the US Gulf of Mexico 1972-1989. NMFS Pascagoula Facility.

National Oceanic and Atmospheric Administration - National Marine Fisheries Service. 2018. Annual Commercial Landings Statistics. Retrieved May 2019 from https://www.st.nmfs.noaa.gov/commercial-fisheries/commerciallandings/annualandings/index.

Orlando, S. P. Jr., L. P. Rozas, G.H. Ward and C.J. Klein. 1993. Salinity characteristics of Gulf of Mexico estuaries. Silver Spring, MD: National Oceanic and Atmospheric Administration, Office of Ocean Resources Conservation and Assessment. 209 pp. 
Pulver, J. R., E. Scott-Denton, and J. A. Williams. 2012. Characterization of the US Gulf of Mexico skimmer trawl fishery based on observer data.

Rattanasatheirn, N., S. Benjakul, W. Visessanguan, and K. Kijroongrojana. 2008. Properties, translucence, and microstructure of Pacific white shrimp treated with mixed phosphates as affected by freshness and deveining. Journal of Food Science 73(1):S31-S40.

Scott-Denton, E., and coauthors. 2006. Skimmer trawl fishery catch evaluations in coastal Louisiana, 2004 and 2005. Marine Fisheries Review 68(1-4):30-35.

Scott-Denton, E., and coauthors. 2012. Characterization of the US Gulf of Mexico and South Atlantic penaeid and rock shrimp fisheries based on observer data. Marine Fisheries Review 74(4):1-27.

Sims, M. R. 2013. Investigating methods to reduce and control sodium levels in shrimp. University of Florida.

Tan, E.-C., and W. Van Engel. 1966. Osmoregulation in the adult blue crab, Callinectes sapidus Rathbun. Chesapeake Science 7(1):30-35.

Zeng, Q. Z., K. A. Thorarinsdottir, and G. Olafsdottir. 2005. Quality changes of shrimp (Pandalus borealis) stored under different cooling conditions. Journal of Food Science 70(7):s459-s466.

Zupanovich, J. 2010. Oxidation and Degradation Products of Common Oxygen Scavengers. Report (Chem Tech Inc., USA, 2002). 


\section{APPENDIX A. SURVEY IRB EXEMPTION}

\section{ACTION ON EXEMPTION APPROVAL REQUEST}

TO:

Julie Lively

SRNR

FROM:

Dennis Landin

Chair, Institutional Review Board

DATE: July 11,2018

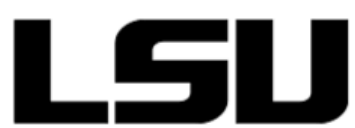

$$
\begin{gathered}
\text { Institutional Review Board } \\
\text { Dr. Dennis Landin, Chair } \\
\text { 130 David Boyd Hall } \\
\text { Baton Rouge, LA } 70803 \\
\text { P: } 225.578 .8692 \\
\text { F: } 225.578 .5983 \\
\text { irb@lsu.edu } \\
\text { Isu.edu/research }
\end{gathered}
$$

RE:

IRB\# E11126

TITLE: $\quad$ Shrimp Quality Enhancement Through Plate Freezing: New Market Opportunities

New Protocol/Modification/Continuation: New Protocol

Review Date: $\underline{7 / 11 / 2018}$

Approved_ $\mathrm{X}$ Disapproved

Approval Date: $\underline{7 / 11 / 2018}$ Approval Expiration Date: $\underline{7 / 10 / 2021}$

Exemption Category/Paragraph: $\underline{2 a}$

Signed Consent Waived?: Yes for online, No for in person.

Re-review frequency: (three years unless otherwise stated)

LSU Proposal Number (if applicable): $\underline{45417}$

Protocol Matches Scope of Work in Grant proposal: (if applicable)

By: Dennis Landin, Chairman

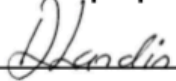

PRINCIPAL INVESTIGATOR: PLEASE READ THE FOLLOWING Continuing approval is CONDITIONAL on:

1. Adherence to the approved protocol, familiarity with, and adherence to the ethical standards of the Belmont Report, and LSU's Assurance of Compliance with DHHS regulations for the protection of human subjects*

2. Prior approval of a change in protocol, including revision of the consent documents or an increase in the number of subjects over that approved.

3. Obtaining renewed approval (or submittal of a termination report), prior to the approval expiration date, upon request by the IRB office (irrespective of when the project actually begins); notification of project termination.

4. Retention of documentation of informed consent and study records for at least 3 years after the study ends.

5. Continuing attention to the physical and psychological well-being and informed consent of the individual participants, including notification of new information that might affect consent.

6. A prompt report to the IRB of any adverse event affecting a participant potentially arising from the study.

7. Notification of the IRB of a serious compliance failure.

8. SPECIAL NOTE: When emailing more than one recipient, make sure you use bcc. Approvals will automatically be closed by the IRB on the expiration date unless the PI requests a continuation.

* All investigators and support staff have access to copies of the Belmont Report, LSU's Assurance with DHHS, DHHS (45 CFR 46) and FDA regulations governing use of human subjects, and other relevant documents in print in this office or on our World Wide Web site at http://www./su.edu/irb 


\section{APPENDIX B. PLATE FROZEN SHRIMP SURVEY}

1) Are you aware of Premium Plate Frozen Shrimp (PFS)?

Yes

No

2) Have you used this product before?

Yes

No

3) Do you currently use this product?

Yes

No

4) Are you aware of Louisiana Limited Wild Plate Frozen Shrimp?

Yes

No

5) Plate Frozen Shrimp are a premium head on, shell on product available yearround for top of the line seafood dishes. PFS are higher quality than IQF shrimp and freeze both faster and more consistently. Do you have a use for a product like this in your restaurant?

Yes

No

6) How much PFS product would you order at one time (in pounds)?

50-100 $\quad 100-500 \quad 500-1000$ Other:

7) How often would you order product?

Daily Weekly Monthly Twice Monthly Other:

8) What size shrimp do you prefer? 
$10 / 15 \quad 16 / 20 \quad 21 / 25 \quad 26 / 30 \quad$ Other:

9) What size box/package do you prefer?

$5 \mathrm{lb}$ box -1 bag

$10 \mathrm{lb}$ box - 1 bag

10lb box- 2 bags (5lb each)

20lb box- 2 bags (10lb each)

$20 l b$ box- 1 bag

Other:

10)Are you interested in learning more about Plate Frozen Shrimp and the Louisiana Limited Plate Frozen Product?

Yes

No

11)How would you like to learn more if answered yes above? (Rank your first, second, and third choice)

Direct Outreach - phone call or email

Send additional information - phone call or email Small group cooking demonstrations

Visit with a fisherman/ dealer on site

12)What is your preferred contact method?

Email:

Phone:

Mailing Address: 


\section{VITA}

Nicholas Alan Haddad, a native of Center Valley, Pennsylvania, received his bachelor's degree in Marine Science and Biology at the University of Tampa in 2017. He is an avid fisherman, outdoorsman, and is passionate about sustainable natural resources. After graduating college, he made the decision to attend Louisiana State University to further his education. Upon completion of his master's degree, he plans to work with recreational and commercial fishermen to achieve a mutual goal of more sustainable fisheries. 